\title{
Um Modelo de Gerenciamento de Riscos para Projetos de Software com Equipes Distribuídas
}

\section{A Risk Management Model for Software Projects with Distributed Teams}

\author{
Alexsandro Souza Filippetto, Robson Lima, Jorge Barbosa \\ Programa de Pós-Graduação em Computação Aplicada - Universidade do Vale do Rio \\ dos Sinos (Unisinos) \\ São Leopoldo, RS - Brasil \\ \{alexsandrofilippetto, robsonklima\}@gmail.com, jbarbosa@unisinos.br
}

\begin{abstract}
The advance of business globalization in recent years is reflected in the area of information systems. Distributed software development (DDS) arises as an alternative that provides a global presence to companies, bringing their teams closer to this new reality. DDS has benefits having teams located in different geographic locations but can also provide to greater risk occurring in projects due to the greater complexity of coordination and communications among their members. Proper risk management through project history analysis decreases the occurrence of planning deviations from project time, cost, and quality. Understanding the benefits of proper risk management discipline practice, this article proposes the Átropos model to assist teams to identify and monitor risks at different points in the life cycle of projects. The work was evaluated by conducting a case study in a distributed software team, with a historical database containing 463 projects developed during the years 2017 and 2018.
\end{abstract}

Keywords. Risk Management; Risk Identification; Risk Response; Risk Prediction; Distributed Software Development.

Resumo. Nos últimos anos observa-se um avanço em direção à globalização dos negócios refletindo-se na área de sistemas de informação. $O$ desenvolvimento distribuído de software (DDS) surge como uma alternativa que proporciona presença global às empresas, aproximando suas equipes dessa nova realidade. ODDS se beneficia por comportar equipes localizadas em diferentes locais geográficos, mas pode também contribuir para maior ocorrência de riscos em projetos, devido à maior complexidade de coordenação e comunicação entre os seus integrantes. O gerenciamento adequado dos riscos, através da análise dos históricos dos projetos desenvolvidos, reduz o risco quanto a desvios do planejamento em relação a tempo, custo e qualidade do projeto. Entendendo os benefícios da prática correta da disciplina de gestão de riscos, este artigo propõe um modelo, intitulado Átropos, para auxiliar as equipes a identificar e acompanhar riscos

Filippetto, A. S., Lima, R. \& Barbosa, J. (2020). A Risk Management Model for Software Projects with Distributed Teams (Um Modelo de Gerenciamento de Riscos para Projetos de Software com Equipes Distribuídas). iSys: Revista Brasileira de Sistemas de Informação (Brazilian Journal of Information Systems), 13(1), 114-143. 
em diferentes momentos do ciclo de vida dos projetos. A avaliação do trabalho foi conduzida através de um estudo de caso em uma equipe distribuída de software, com o uso de uma base de dados histórica de projetos, com 463 projetos desenvolvidos durante os anos de 2017 e 2018.

Palavras-Chave. Gerenciamento de Riscos; Identificação de Riscos; Resposta aos Riscos; Predição de Riscos; Desenvolvimento Distribuído de Software.

\section{Introdução}

Mercados nacionais têm se transformado em mercados globais, criando formas de cooperação que vão além das fronteiras dos países, incentivando o Desenvolvimento Distribuído de Software (DDS). As instituições têm adotado o DDS ao buscar por profissionais com habilidades específicas, mão de obra de menor custo e presença globalizada. No entanto, apesar dos benefícios, a distância entre as equipes pode contribuir para o aumento de riscos aos projetos. De acordo com a pesquisa de Ambler (2012) quanto maior é o nível de distribuição geográfica, maior é o risco devido aos desafios de comunicação e coordenação, resultando em menor taxa de sucesso para projetos distribuídos. Cerca de $60 \%$ dos projetos de software co-localizados são bemsucedidos, enquanto $25 \%$ destes não atingem seus objetivos. Quando analisados projetos distribuídos, as chances de sucesso caem para 50\% [Shrivastava et al. 2014].

O gerenciamento de riscos está sendo considerado, cada vez mais, uma das principais atividades dos gerentes de projetos [Sommerville 2015]. O risco de projeto é um evento ou condição incerta que, se ocorrer, provocará um efeito positivo ou negativo em um ou mais objetivos do projeto tais como escopo, cronograma, custo e qualidade [PMBOK 2017]. Um estudo mostra que, nas empresas de TI, a gestão de riscos é a disciplina menos praticada da gestão de projetos [Sulaman et al. 2013]. No entanto, nos projetos em que se utilizou gestão de riscos, $70 \%$ dos riscos foram detectados e $90 \%$ puderam ser evitados [Tianyin 2011]. Segundo o PMBoK, as organizações devem estar comprometidas com uma abordagem constante da gestão de riscos ao longo do projeto. Avançar em um projeto sem abordar a gestão de riscos de forma proativa pode comprometer o seu sucesso, devido ao surgimento de ameaças não gerenciadas [PMBOK 2017].

Os riscos em projetos são abordados em dois níveis: riscos individuais e riscos gerais. No primeiro nível, onde cada risco é identificado e gerenciado, estes são atrelados às atividades do projeto [PMBOK 2017]. Com isso, deve-se compreender como o indivíduo se comporta para atingir os objetivos de uma atividade, a fim de identificar os riscos inerentes a este trabalho. Dessa forma, esse artigo propõe uma abordagem para o gerenciamento de riscos através do uso da Teoria da Atividade [Vygotsky 2015]. Nessa teoria, Leontiev (2019) evoluiu a visão de Vygostky da ação individual para a atividade (que é coletiva) e Engeström (2014) evoluiu o conceito de atividade para um sistema de atividades, onde as atividades não existem de forma isolada, sendo parte de um sistema mais amplo de relações com outras atividades. Os elementos da teoria são aplicados para categorização da Estrutura Analítica de Riscos (EAR) com o objetivo de auxiliar os gestores na identificação da causa raiz dos riscos e suas interdependências. 
O dinamismo das atividades nas organizações e a busca por novos produtos e segmentos de mercado, tornam o gerenciamento de projetos uma área cada vez mais complexa [Filippetto et al. 2016]. Nesse sentido, o uso de conceitos introduzidos pela computação ubíqua [Barbosa et al. 2015], como os históricos de contextos por exemplo, se mostra uma alternativa para auxiliar os gerentes na condução dos projetos. Um sistema de computação ubíqua deve ser minimamente intrusivo, para isso este sistema deve estar ciente de seu contexto [Knappmeyer et al. 2013], ou seja, o sistema deve conhecer informações relativas ao usuário e seu ambiente. Com isso o sistema tem maior capacidade de se adaptar as necessidades dos usuários, tornando-se mais proativo [Dey et al. 2001], onde a partir de análises de histórico de contextos (por exemplo, a predição de contextos) torna-se possível agir de forma proativa [Rosa et al. 2016].

Este artigo propõe um modelo, intitulado Átropos, para o gerenciamento de riscos dos projetos de software com equipes distribuídas. O modelo Átropos foi desenvolvido considerando um conjunto de melhores práticas para a gestão de riscos [PMBOK 2017; PMI 2016; Sommerville 2015; Pressman e Maxim 2016], além da identificação de necessidades através do estudo de trabalhos relacionados, como o uso de recomendação para auxiliar na condução dos projetos.

Como principal diferencial científico, o modelo utiliza a análise sobre os históricos dos projetos para recomendar riscos que possuem relação com o projeto em execução. Os objetivos principais do modelo Átropos são: (i) auxiliar na identificação dos riscos através da recomendação; (ii) aumentar a colaboração dos stakeholders durante a identificação e análise de riscos; (iii) quantificar os riscos; (iv) priorizar os riscos. Assim a pesquisa buscou respostas para as seguintes questões: RQ1. "É possível através da análise das características e similaridade dos projetos inferir riscos na fase de identificação dos riscos?”; RQ2. "A colaboração na identificação dos riscos pelos stakeholders pode melhorar a identificação de riscos?".

Este estudo assume como hipótese que o uso dos históricos dos projetos pode fornecer informações importantes sobre projetos executados na empresa, além de permitir uma análise sobre as lições aprendidas. Assim, o modelo Átropos tem como objetivo identificar riscos ocorridos em projetos similares para permitir a recomendação de riscos, possibilitando assim que os gestores possam tomar as devidas ações para alcançar os objetivos do projeto. Para avaliar estas recomendações, foi realizado um estudo de caso, para comprovar a hipótese. No estudo de caso 11 projetos com diferentes características foram cadastrados, para avaliar as recomendações e o uso por equipes de desenvolvimento distribuído de software.

Este artigo está organizado da seguinte forma: a seção 2 aborda os principais conceitos relacionados ao trabalho, além de analisar os trabalhos relacionados ao tema proposto, destacando suas características e comparando-os com o modelo Átropos; já a seção 3 descreve a metodologia aplicada neste estudo, enquanto que a seção 4 apresenta o modelo Átropos e o protótipo desenvolvido, e, por fim, a seção 5 traz as análises e resultados do estudo de caso enquanto que as considerações finais são apresentadas na seção 6. 


\section{Revisão da Literatura}

Esta seção sistematiza os principais conceitos utilizados para desenvolvimento do modelo. Inicialmente são apresentados os conceitos referentes a risco e ao gerenciamento de riscos. Após são abordados os fundamentos do desenvolvimento distribuído de software. O estado da arte da teoria da atividade é descrito, com o objetivo de mostrar como a teoria pode contribuir para a categorização dos riscos. Por fim, os trabalhos relacionados e uma comparação com o modelo Átropos são apresentados.

\subsection{Riscos e Gerenciamento de Riscos}

Riscos são eventos ou condições incertas que em ocorrendo irão causar um efeito negativo ou positivo nos objetivos do projeto [PMBOK 2017]. Muitos eventos podem ocorrer durante a execução do projeto, esses eventos geram uma situação em que poderão causar um impacto no projeto, podendo ter uma ou mais causas.

A gestão de riscos é geralmente definida como um conjunto de princípios e práticas que visam identificar, analisar e gerar respostas aos fatores de risco com o objetivo de melhorar as chances de alcançar os resultados do projeto [Pressman e Maxim 2016]. O processo de gerenciamento de riscos é um processo interativo, que deve continuar durante todo o projeto. A constância deste processo permite a adaptação das análises com as informações que surgem durante a evolução do projeto. Portanto, uma vez traçados os planos, a evolução deve ser monitorada [Sommerville 2015].

Os riscos em projetos podem ser analisados através de duas abordagens: reativa e proativa. $\mathrm{Na}$ forma reativa aceita-se o risco e este pode ser monitorado ao longo do projeto. Para estes casos o gerenciamento o risco deve reservar recursos para enfrentar os riscos caso estes se tornem problemas. Já uma abordagem proativa se inicia antes da execução técnica do projeto, visando identificar os riscos antes de se tornarem problemas.

Neste contexto, os riscos são identificados, analisados quanto à probabilidade de ocorrência e impactos e definidas estratégias de resposta aos riscos, devendo ainda os riscos serem monitorados ao longo do projeto [Pressman e Maxim 2016]. O processo de gerenciamento de riscos envolve os seguintes estágios: identificação, análise dos riscos, planejamento e monitoramento.

O processo de identificação de riscos envolve a determinação dos riscos que podem afetar o projeto e a documentação das suas características. A análise dos riscos é dividida em duas etapas, a análise qualitativa compreende o processo de priorização de riscos para análise ou ação posterior, através da avaliação e combinação de sua probabilidade de ocorrência e impacto. A análise quantitativa tem por objetivo analisar numericamente o efeito dos riscos nos objetivos do projeto [PMBOK 2017].

Através da análise de riscos, pode-se obter uma lista priorizada de riscos, onde destacam-se os riscos de maior importância para o projeto, possibilitando focar maiores esforços gerenciais nos mesmos. Deste modo, as equipes devem identificar quais os riscos que causam maior impacto e consequentemente contribuir para aumentar as chances de falha do projeto [Joia et al. 2013]. 
Após a identificação e análise, é possível planejar as respostas aos riscos. Neste processo desenvolvem-se opções e ações para aumentar as oportunidades e reduzir as ameaças aos objetivos do projeto. Por fim, o processo envolve controlar os riscos, implementando planos de respostas a estes, acompanhando os riscos identificados, monitorando riscos residuais, identificando novos riscos e avaliando a eficácia do processo de gerenciamento dos riscos durante todo o projeto [PMBOK 2017].

\subsection{Desenvolvimento Distribuído de Software}

O Desenvolvimento de Software Distribuído (DDS) se caracteriza pela cooperação entre os departamentos e seus grupos de desenvolvedores, localizados em cidades ou países diferentes e trabalhando em conjunto. $\mathrm{O}$ desenvolvimento de software tem se tornado mais caro e menos competitivo quando localizado no mesmo espaço físico, mesma organização ou até mesmo país. O avanço na economia, a sofisticação dos meios de comunicação, assim como a exigência por menores custos têm incentivado este tipo de abordagem. Alguns fatores contribuíram para o surgimento do DDS. Entre eles destacam-se: necessidade de recursos globais, proximidade do mercado local, exploração de fusos horários diferentes e mão de obra mais barata [Audy e Prikladnicki 2007].

A distância entre os stakeholders pode trazer também dificuldades na coordenação do trabalho, assim como diferenças culturais e temporais o que traz maior desafio para a gerência do projeto. Em contraponto, segundo a International Data Group, em média pode-se atingir uma economia entre $25 \%$ e $50 \%$ em termos de custo quando os projetos são implementados utilizando equipes de desenvolvimento distribuídas, justificando a preferência das empresas pelo uso do DDS [Audy e Prikladnicki 2007].

Além do mais, o tamanho de uma equipe distribuída é um fator importante, pois a abundante conectividade atual pode encorajar as equipes a crescerem de maneira descontrolada. A sala de conferências virtual pode se expandir, pelo menos em teoria, em direção a um espaço quase infinito. $\mathrm{O}$ aumento da quantidade de participantes em um projeto também aumenta, assim como a sua complexidade de gestão, elevando a quantidade de riscos relacionados à comunicação [Bradner et al. 2005].

Ambientes de trabalho distribuídos virtualmente podem propiciar também maiores conflitos, o que aumenta os riscos relativos à recursos humanos. Devido aos recursos do DDS, os membros de uma equipe de desenvolvimento de software não podem se comunicar face a face facilmente, o que pode causar mais conflitos entre diferentes equipes, quando comparadas aos métodos tradicionais [Jiang et al. 2017]. Ainda se referindo a problemas relacionados a recursos humanos, a falta de disciplina e insuficiente transparência em projetos que utilizam DDS podem ocultar possíveis riscos que tendem a ser identificados tardiamente [Calefato e Ebert 2019].

Diante do cenário exposto, entende-se que a gestão de riscos deve se tornar acessível e facilitada em todas as camadas do gerenciamento dos projetos. Todas as partes interessadas devem precisam participar do levantamento dos riscos, aumentando a cooperação e incentivando a participação nesta área, que se torna cada vez mais determinante para o sucesso dos projetos. 


\subsection{Teoria da Atividade}

A teoria da atividade é baseada em conceitos da escola russa de psicologia, tendo início com os trabalhos de Vygotsky, desenvolvidos entre as décadas de 1920 e 1930. Essa teoria procurava explicar as interações dos seres humanos e suas atividades no mundo real. Segundo a teoria, o ser humano é moldado pela cultura em que está inserido, atuando com ou através de outras pessoas nas organizações e na comunidade [Allen et al. 2011]. Vygotsky, em sua teoria, enfatiza a importância do papel das ferramentas e artefatos na mediação das ações humanas. Além disso, também é destacado o papel crucial que outras pessoas têm na contribuição e na participação da atividade humana individual dentro de um contexto social [Engeström 2014].

Com base no trabalho de Vygotsky, Leontiev introduziu o conceito da atividade, apresentando a diferença entre ação humana e a atividade. Uma atividade deve transformar o objeto em resultados ou no objetivo [Leontiev 2019]. Neste sentido as ações são executadas a fim de constituir uma atividade, fazendo sentido muitas vezes apenas neste contexto. Enquanto que a atividade deve satisfazer uma necessidade, sendo transformado no objetivo [Allen et al. 2011].

Engeström (2014), expandiu o sistema de atividades para incluir novos elementos, como a comunidade, a divisão do trabalho e normas ou regras, apresentando a terceira geração para a teoria. Nesta terceira geração, foi introduzido o conceito de sistemas de atividades e inclui novos elementos que permitem a análise e a compreensão deste sistema. Ao expandir os conceitos, Engeström procurou demonstrar um contexto social maior, adicionando a comunidade como um componente em separado e argumentando que as relações entre os componentes do modelo são mediadas de diferentes maneiras [Allen et al. 2011]. De acordo com Engeström (2014), as atividades não existem de forma isolada, elas são parte de um sistema mais amplo de relações. A Tabela 1 apresenta os elementos que compõe o sistema de atividades e sua definição.

\section{Tabela 1. Elementos da Teoria da Atividade}

\begin{tabular}{|l|l|}
\hline \multicolumn{1}{|c|}{ Elemento } & \multicolumn{1}{|c|}{ Definição } \\
\hline Sujeito & Indivíduo ou grupo que é escolhido para a atividade \\
\hline Regras & $\begin{array}{l}\text { Se referem aos regulamentos explícitos e implícitos, normas e convenções que } \\
\text { restringem as ações e interações dentro do sistema da atividade. }\end{array}$ \\
\hline Comunidade & $\begin{array}{l}\text { Indivíduos e/ou subgrupos que compartilham o mesmo objeto do sujeito. A } \\
\text { comunidade situa a atividade em estudo dentro do contexto sociocultural daqueles } \\
\text { sujeitos que compartilham o mesmo objeto da atividade. O relacionamento entre os } \\
\text { sujeitos e a comunidade é mediado por regras e divisão do trabalho. }\end{array}$ \\
\hline $\begin{array}{l}\text { Divisão de } \\
\text { Trabalho }\end{array}$ & $\begin{array}{l}\text { Refere-se tanto a divisão horizontal de tarefas entre os membros da comunidade } \\
\text { quanto na divisão vertical de poder e status. }\end{array}$ \\
\hline Objeto & $\begin{array}{l}\text { Refere-se à 'matéria-prima' em que a atividade é dirigida e que é moldada e } \\
\text { transformada em resultados, com a ajuda dos artefatos mediadores. O objeto representa } \\
\text { a natureza objetiva da atividade humana e permite que os indivíduos controlem seus } \\
\text { próprios motivos e comportamento ao realizar a atividade. O termo objetivo pode ser } \\
\text { entendido no lugar de objeto para enfatizar a natureza objetiva da atividade humana. }\end{array}$ \\
\hline $\begin{array}{l}\text { Artefatos } \\
\text { Mediadores }\end{array}$ & $\begin{array}{l}\text { Faz a mediação entre o sujeito e o objeto em uma atividade. Pode ser qualquer coisa } \\
\text { usada pelo sujeito no processo de transformar o objeto em resultado - pode ser algo } \\
\text { físico ou de conhecimento. }\end{array}$ \\
\hline
\end{tabular}


Um elemento importante introduzido a teoria da atividade por Engeström, é de que a atividade está em constante desenvolvimento como resultado de contradições, tensões e instabilidade, levando em consideração as necessidades da comunidade e do sujeito. Essas tensões e contradições devem ser entendidas neste contexto, para que a mudança ocorra a fim de atingir o objetivo da atividade [Engeström 2014].

As contradições são essenciais para o sistema de atividade, pois são uma fonte dinâmica de transição, análise e desenvolvimento. A ocorrência de contradições no sistema faz com que formas e padrões de trabalho sejam questionados surgindo novas formas de organização. As novas formas de trabalho surgem, tendo em vista que regras e procedimentos são questionados, reinterpretados, reformulados e/ou modificados a fim de atender aos objetivos e necessidades de todos os participantes [Engeström e Sannino 2014]. Desta forma, as contradições são como uma força motriz para a mudança ou transformação da atividade [Engeström 2014]. De acordo com Engeström (2014) sempre há constante construção e renegociação dentro do sistema de atividade.

Um projeto é composto por um conjunto de atividades que devem ser executadas de acordo com o planejamento, para se chegar a um objetivo definido através do escopo do projeto [PMBOK 2017]. Os elementos apresentados por Engeström (2014) que compõem a teoria da atividade (Sujeito, Regras, Comunidade, Divisão do Trabalho, Objeto e Artefatos Mediadores), pressupõe grupos que afetam ou influenciam a execução de uma atividade. Assim, esses elementos, são utilizados no modelo para categorizar a EAR (Estrutura Analítica de Riscos).

A EAR agrupa os riscos de acordo com a categoria, afim de auxiliar identificação da relação dos riscos ou a causa raiz dos riscos. O uso de uma teoria que define como as atividades são executadas para se alcançar um objetivo ou resultado, permite aos gestores correlacionarem os riscos em uma mesma categoria para realizar uma análise ampla para respostas aos riscos. Neste cenário, por exemplo, uma determinada resposta de mitigação pode reduzir a probabilidade ou impacto de um grupo de riscos que constam em uma mesma categoria definida no modelo pela Teoria da Atividade.

\subsection{Trabalhos Relacionados}

Os trabalhos relacionados a este estudo, podem ser agrupados em duas categorias: (i) novas metodologias ou modelos para gestão de riscos; (ii) trabalhos que realizem a recomendação de riscos ou respostas aos riscos. Nesse sentido são destacados quatro trabalhos que são apresentados nesta seção.

O trabalho apresentado por Qazi et al. (2016) realiza uma abordagem de como é tratada a complexidade dos projetos e sua relação com os riscos identificados. A partir deste estudo, os autores propõem um modelo para mensurar as melhores estratégias de mitigação dos riscos do projeto baseado nas interdependências dos riscos, considerando o quanto a complexidade dos projetos influência nestes riscos. Utiliza-se em sua estrutura redes bayesianas para identificar e propagar os pesos da interdependência dos riscos e o quanto isso irá impactar nos objetivos do projeto.

O modelo descrito por Zhang para a seleção de estratégias de mitigação de riscos é apresentado em dois trabalhos selecionados [Zhang 2016; Zhang e Fan 2014], onde então é apresentado um estudo para mensurar a interdependência dos riscos do 
projeto, uma vez que os riscos possuem relação com outros e afetam os projetos de forma conjunta. Com a identificação da interdependência dos riscos, estes dados são utilizados como base para um modelo voltado a auxiliar nas decisões de respostas aos riscos. A interdependência dos riscos é um dos elementos importantes para definir a complexidade dos projetos, assim permitindo uma melhor seleção das estratégias para mitigação dos riscos.

O objetivo do estudo apresentado por Fan et al. (2015) é auxiliar os gestores de projetos com estratégias para respostas aos riscos baseadas no histórico de casos de projetos similares. Os autores propõem um modelo dividido em cinco etapas: (1) na primeira etapa o problema atual da resposta ao risco no projeto é considerado o caso alvo e o mesmo é representado em relação aos históricos; (2) são buscados os casos históricos disponíveis na base de dados; (3) então são buscados os casos históricos semelhantes, medindo a similaridade entre cada histórico disponível e o caso tomado como alvo; (4) após então, são trazidas as estratégias de respostas aos riscos; (5) por fim, são geradas as estratégias desejáveis de resposta aos riscos do projeto. Ao final do processo, o valor para mitigação e retorno de aplicação da estratégia é calculada para cada estratégia ou conjunto aplicados. Assim, orientando o gerente de projetos para seleção do conjunto de estratégias mais adequadas a configuração do projeto (considerando custos e retorno sobre o investimento).

O trabalho de Fang e Marle (2012) apresenta um Sistema de Apoio a Decisão (SAD) para a modelagem do gerenciamento de riscos em projetos. O framework SAD é composto por cinco fases para gestão dos riscos: (1) identificação da rede de riscos; (2) avaliação da rede de riscos; (3) análise da rede de riscos; (4) planejamento de resposta aos riscos; (5) monitoramento e controle dos riscos. A partir da identificação e análise da rede de riscos, então o modelo aplica a simulação a rede de riscos já identificados, o que permite reavaliar os riscos e suas prioridades, sugerir e testar ações de mitigação, e tem como objetivo apoiar os gerentes de projetos na tomada de decisões sobre ações de respostas aos riscos. Através da identificação da rede de riscos e a propagação aplicada pelo modelo, o framework permite que o gerente de projetos obtenha novas informações sobre os riscos, a relação entre os riscos e o comportamento global da rede de riscos. Além disso, o trabalho permite testar e avaliar os planos de ação para mitigação propostos através da simulação.

\subsubsection{Análise Comparativa dos Trabalhos Relacionados}

Esta seção apresenta um comparativo entre os trabalhos relacionados e o modelo Átropos. A Tabela 2 mostra os critérios que foram utilizados para comparação, tendo como primeiro critério qual das principais etapas da gestão do risco os artigos abordam ou se propõem a auxiliar (identificação, análise, estratégia de resposta ou monitoramento e controle). Foi realizada uma avaliação dos trabalhos que subsidiam os gestores com novas informações sobre riscos, através de recomendação, e por consequência, qual técnica é abordada para recomendação. Além disso, o comparativo mostra se o trabalho trata a categorização da EAR (Estrutura Analítica dos Riscos) com o objetivo de identificação da causa dos riscos, ainda é apresentado se o modelo permite a colaboração entre os diferentes stakeholders do projeto, seja na identificação dos riscos ou na seleção de estratégias de respostas.

\section{Tabela 2. Comparação dos Trabalhos Relacionados}

iSys: Revista Brasileira de Sistemas de Informação (iSys: Brazilian Journal of Information Systems) http://seer.unirio.br/index.php/isys/ 


\begin{tabular}{|l|l|l|l|l|l|}
\hline Autores & $\begin{array}{l}\text { Etapa de Gestão } \\
\text { de Riscos Abordada }\end{array}$ & Recomenda & $\begin{array}{l}\text { Técnica } \\
\text { Recomendação }\end{array}$ & EAR & Colaboração \\
\hline $\begin{array}{l}\text { QQazi et al. } \\
2016]\end{array}$ & Análise, Resposta & Não & Não se aplica & $\begin{array}{l}\text { Não se } \\
\text { aplica }\end{array}$ & Não \\
\hline $\begin{array}{l}\text { [Zhang } \\
\text { e Fan, Zhang } 2014]\end{array}$ & Análise, Resposta & Não & Não se aplica & $\begin{array}{l}\text { Não se } \\
\text { aplica }\end{array}$ & Não \\
\hline $\begin{array}{l}{[\text { Fan et al. }} \\
2015]\end{array}$ & Resposta & Sim & Histórico & $\begin{array}{l}\text { Não se } \\
\text { aplica }\end{array}$ & Não \\
\hline $\begin{array}{l}\text { [Fang e } \\
\text { Marle, 2012] }\end{array}$ & $\begin{array}{l}\text { Identificação, } \\
\text { Análise, Resposta, } \\
\text { Controle }\end{array}$ & Não & Não se aplica & $\begin{array}{l}\text { Não se } \\
\text { aplica }\end{array}$ & Não \\
\hline $\begin{array}{l}\text { Modelo } \\
\text { Átropos }\end{array}$ & $\begin{array}{l}\text { Identificação, } \\
\text { Análise, Resposta, } \\
\text { Controle }\end{array}$ & $\begin{array}{l}\text { Sim (Riscos, } \\
\text { Respostas) }\end{array}$ & $\begin{array}{l}\text { Histórico de } \\
\text { Contexto }\end{array}$ & $\begin{array}{l}\text { Sim, } \\
\text { Teoria da } \\
\text { Atividade }\end{array}$ & Sim \\
\hline
\end{tabular}

Os trabalhos apresentados por Qazi et al. (2016), Zhang (2016) e Zhang e Fan (2014) tratam as etapas de análise e resposta aos riscos. Somente o trabalho apresentado por Fang e Marle (2012) contempla todas as quatro etapas para o gerenciamento de riscos.

O modelo apresentado por Fan et al. (2015) aborda a recomendação de resposta aos riscos. O modelo baseia-se no histórico de projetos executados que tenham o mesmo risco identificado, assim, buscando no histórico respostas já cadastradas para recomendá-las ao novo projeto.

Considerando o resultado do comparativo entre os trabalhos, o modelo apresentado nesta proposta se diferencia dos demais trabalhos em três pontos principais: (1) a proposta aborda todas as etapas da gestão de riscos de uma forma colaborativa, permitindo que todos os envolvidos da equipe possam contribuir ao longo do projeto, tornando assim mais ágil o processo para mitigação dos riscos; (2) propõe o uso da Teoria da Atividade para categorização da EAR, facilitando o agrupamento dos riscos com o objetivo de auxiliar na identificação da causa dos riscos; (3) trata a recomendação de riscos no início de um novo projeto, através do uso dos históricos dos projetos já executados, através das características em comum dos projetos.

\section{Metodologia}

Para buscar responder as questões de pesquisa apresentadas neste trabalho, foi utilizada uma abordagem de pesquisa através da aplicação de um estudo de caso em uma empresa de desenvolvimento de software. Um estudo de caso é um estudo empírico que busca determinar ou testar uma teoria ou hipótese, sem que o pesquisador intervenha sobre o objeto pesquisado, mas apresente sua interpretação a partir do ponto de vista estudado [Gerhardt e Silveira 2009].

A partir da definição das questões de pesquisa (RQ1 e RQ2), este estudo buscou confirmar a hipótese do uso dos históricos de projetos executados para recomendar riscos a novos projetos. Adicionalmente, o estudo visou descobrir se a colaboração dos stakeholders auxiliou na identificação de riscos.

O estudo foi planejado de forma a permitir que a avaliação do modelo fosse executada em diferentes cenários. Neste sentido, 11 projetos foram utilizados. Estes projetos foram escolhidos de forma a permitir a análise sobre diferentes circunstâncias 
ou características. De acordo com as características, os projetos foram categorizados em 8 grupos. $\mathrm{O}$ agrupamento foi realizado de acordo com a área de atuação e tamanho do projeto (pequeno - até 300hs, médio - até 1000hs, grande - acima de 1000hs), considerando que todos tratam de desenvolvimento distribuído de software.

Inicialmente realizou-se uma pesquisa buscando trabalhos que apresentassem modelos ou pesquisas relacionadas a gestão de riscos em projetos. A partir dos artigos e resultados obtidos nesta pesquisa, foram elencados os trabalhos que tinham relação com o modelo Átropos. O estudo deles permitiu a discussão de lacunas de pesquisa na gestão dos riscos em projetos, descritas na seção 2.4.1. A partir das oportunidades identificadas para a gestão de riscos, o estudo seguiu as etapas apresentadas nas próximas seções.

\subsection{Concepção e Desenvolvimento do Modelo}

Analisando os trabalhos relacionados e as lacunas referentes ao gerenciamento de riscos, foi concebido o modelo Átropos, considerando um conjunto de melhores práticas para a gestão de riscos [PMBOK 2017; PMI 2016; Sommerville 2015; Pressman e Maxim 2016], contemplando todas as fases para a gestão de riscos em projetos (identificação, análise, planejamento de respostas e monitoração dos riscos). Além de contemplar as fases para gestão, o modelo permite a colaboração entre a equipe responsável pelo projeto, com o objetivo de dar suporte ao desenvolvimento com equipes distribuídas, utilizando-se de conceitos da computação móvel.

O modelo permite a análise das informações através de um conjunto de Bots que monitoram a aplicação para a geração da recomendação de novos riscos ao projeto. É considerada a similaridade dos projetos armazenados no histórico com as características do projeto em execução. Os Bots são componentes de software autônomos que possuem tarefas e buscam os objetivos definidos para si, podendo simular as ações repetidas vezes [Yang et al. 2019]. Desta forma, no modelo Átropos, os Bots analisam os eventos (alterações no projeto, alteração de cronograma, um risco que se torna problema) que possam ocorrer no projeto de forma contínua, para que novas recomendações sejam realizadas.

Para avaliação do modelo, foi desenvolvido um protótipo para uso durante a execução dos projetos, através de uma interface mobile. O desenvolvimento do modelo Átropos é detalhado na seção 4.

\subsection{Coleta de Dados Históricos}

A empresa do ramo de automação de software da área financeira, objeto do estudo de caso aplicado, possui informações armazenadas sobre seus projetos. Para carregar a base de dados histórica, foram extraídos dados de 463 projetos, executados entre os anos de 2017 e 2018, na área de desenvolvimento de software.

A base histórica contém projetos com diferentes características, desenvolvidos de forma distribuída ou não. Estas características, assim como sua localização são armazenadas na base de dados. Quando os projetos são distribuídos, é utilizado o formato de outsourcing, com parte da equipe atuando em outros estados e uma parte da equipe na matriz no Rio Grande do Sul. O uso de características diferentes de projetos permite uma análise sobre os diferentes contextos para a recomendação dos riscos. 
Esta base de dados histórica serviu de entrada para o Átropos com o objetivo de conter diferentes projetos que permitissem ao modelo realizar a análise de similaridade para os novos projetos. Assim, a análise realizada pelo Átropos pode recomendar riscos aos projetos com base nesse histórico já executado. Com o Átropos carregado com os históricos de projetos, foi aplicado o estudo de caso para avaliação. A base histórica de projetos é utilizada para análise dos riscos ocorridos em projetos similares já executados, para permitir ao modelo recomendar riscos ao novo projeto que se inicia.

A etapa para coleta de dados históricos, se fez necessária para se realizar a análise sobre um conjunto de dados de projetos já executados. Desta forma, é possível avaliar se o uso das características de cada projeto contribuiu para a recomendação de riscos de acordo com o contexto do projeto em execução.

\subsection{Definição e Aplicação do Estudo de Caso}

Com o propósito de responder as questões de pesquisa apresentadas foi realizado um estudo de caso que avaliasse a recomendação de riscos aos projetos. Com o uso da base histórica contendo um conjunto de projetos concluídos, novos projetos foram cadastrados, para serem utilizados no estudo de caso.

Para o estudo de caso, foi utilizado o modelo de outsourcing, onde uma parte da equipe atuou em São Paulo e outra no estado do Rio Grande do Sul. Durante o período de 4 semanas, 5 profissionais de desenvolvimento de software utilizaram o protótipo, cadastrando seus principais projetos, riscos e atividades, gerenciando os riscos dos projetos.

Os integrantes da equipe avaliaram as recomendações geradas para os 11 projetos utilizados. Eles deveriam apropriar os riscos ao novo projeto ou recusa-los, permitindo assim uma avaliação das recomendações realizadas.

Para assegurar a significância estatística do estudo de caso, selecionou-se um conjunto de projetos na área de desenvolvimento de software construídos para diversos segmentos, assim, o modelo para recomendação foi testado com diferentes configurações.

Além da recomendação, o estudo de caso avaliou as interações da equipe com o uso do protótipo para identificação, análise e acompanhamento dos riscos, durante a execução dos projetos. A equipe que desenvolveu os projetos estava distribuída em dois Estados do Brasil (São Paulo e Rio Grande do Sul). Esta configuração permitiu que fosse avaliada a colaboração com o desenvolvimento envolvendo equipes distribuídas geograficamente. Os resultados dessa fase são apresentados e discutidos na seção 5 .

\section{Modelo Átropos}

Um projeto envolve incertezas, o que implica na necessidade de um efetivo gerenciamento dos riscos. O gerenciamento dos riscos consiste na identificação dos riscos e um tratamento adequado para minimizar seus efeitos no projeto. Portanto o gerenciamento dos riscos é uma área estratégica a ser tratada, a fim de manter o andamento do projeto de acordo com sua linha de base.

O gerenciamento de riscos é importante para projetos de software devido à dinâmica e incerteza que os permeia. Más definições, erros nas estimativas de prazos ou 
mudanças mal especificadas são alguns exemplos de riscos que podem impactar em um projeto de software. O processo de gerenciamento de riscos é um processo interativo que deve continuar durante todo o ciclo de vida do projeto, permitindo a adaptação das análises com as informações que surgem durante a evolução do projeto [Sommerville 2015].

Neste contexto, esta seção propõe um modelo, denominado Átropos, para gestão de riscos para desenvolvimento distribuído de software, e recomendação de riscos, onde é abordada a gestão de riscos de uma forma proativa.

\subsection{Gerenciamento de Riscos}

Uma visão do modelo e das etapas que este aborda pode ser vista na Figura 1. Os módulos Identificação de Riscos e Gestão de Problemas contemplam as fases para gestão dos riscos, e os demais módulos (Entrada, Módulo de Contexto e Assistente de Monitoração) apoiam com informações e análises para a recomendação dos riscos ao projeto.

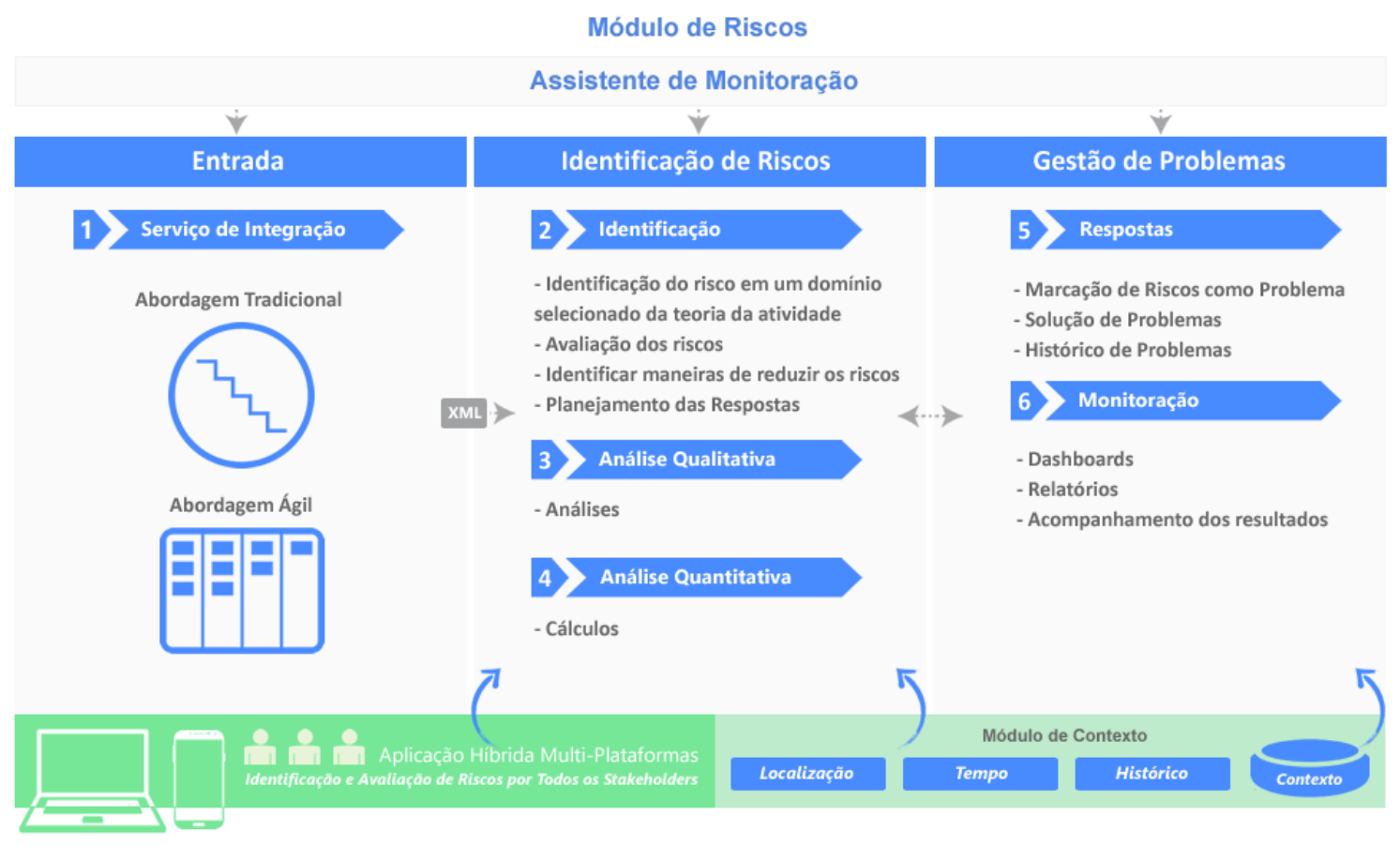

Figura 1. Modelo de Gerenciamento de Riscos

O gerenciamento de riscos possui como entrada um conjunto de atividades do projeto, seja esta entrada através de um cronograma ou tarefas cadastradas em um quadro de Kanban por exemplo. Essa estrutura permite que as empresas utilizem suas ferramentas para controle de atividades sem necessidade de interferência do modelo para gerenciamento dos riscos. Sendo as atividades exportadas para uma saída em XML, então, o assistente de monitoramento importa as informações em uma estrutura própria para uso do modelo. O modelo é organizado em quatro módulos principais:

- Entrada: o serviço de integração, disponibilizado no módulo de entrada, tem como objetivo realizar a carga inicial para o modelo a partir de uma origem de informações de projetos que sejam disponibilizados. Este módulo tem como objetivo permitir que projetos já cadastrados em 
alguma ferramenta possam ser integrados ao modelo para gestão dos riscos;

- Identificação de Riscos: a partir da entrada de um novo projeto e suas atividades, são identificados os riscos para realização do projeto, seguindo a categorização a partir do modelo da teoria da atividade (Objeto, Sujeito, Regras, Divisão do Trabalho, Comunidade, Artefatos Mediadores). Após a identificação dos riscos, então é realizada a avaliação quanto a sua probabilidade e impacto. Com o cadastro das informações de impacto e probabilidade, então é realizado um ranking de prioridades, com os riscos ordenados de acordo com os que possuem maior probabilidade ou impacto no projeto. Neste módulo também deve ser realizada a análise dos riscos, para que seja realizada uma avaliação qualitativa e quantitativa dos riscos;

- Gestão de Problemas: a partir da ocorrência de um evento onde o risco se torna um problema, o risco é marcado com essa ocorrência. Assim são armazenadas informações necessárias para o gerenciamento dos riscos, tais como, localização, tempo, impacto, resposta e solução caso o tenha;

- Módulo de Contexto: O módulo de contextos monitora e armazena as informações referentes ao contexto dos riscos e eventos durante a execução do projeto, permitindo assim que para projetos futuros os históricos de contextos sejam pesquisados para uma recomendação dos riscos e problemas ocorridos, com o objetivo de melhorar o desempenho em novos projetos a partir do gerenciamento mais efetivo.

Para categorizar os riscos utiliza-se uma estrutura analítica de riscos (EAR) baseada no conceito da Teoria da Atividade [Engeström 2014]. A representação das atividades do projeto possui relação com outras classes do domínio da aplicação no âmbito da teoria da atividade. Já os riscos do projeto são categorizados seguindo o modelo da teoria da atividade através do relacionamento das classes de risco com a atividade. A Figura 2 apresenta a relação entre o domínio das atividades e os riscos do projeto.

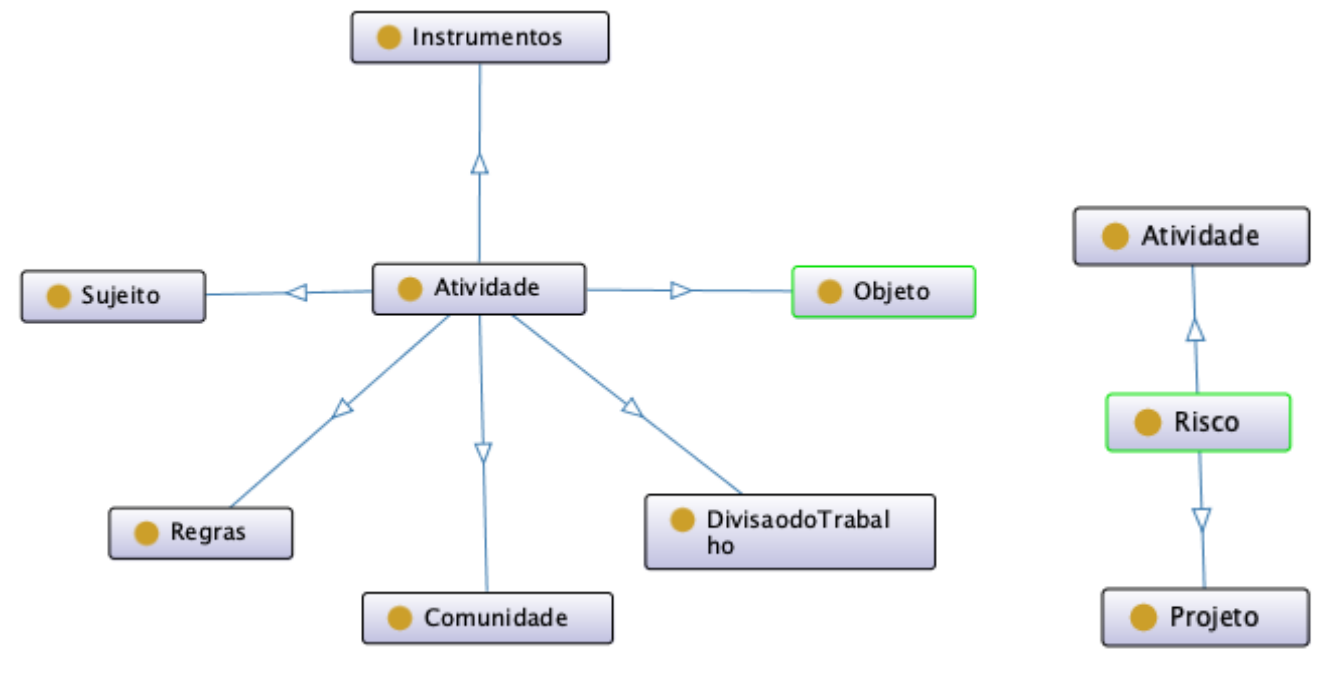

Figura 2. Modelo de Atividades e Riscos 
A atividade a ser executada é representada pela classe Atividade, que além das informações básicas sobre a descrição da tarefa a ser executada, é composta por um conjunto de relações que expressam o conceito aplicado sobre a teoria da atividade. A classe Sujeito representa o indivíduo que é escolhido sob o ponto de vista da análise para execução da atividade. O sujeito é a representação do indivíduo dentro do contexto de um projeto, onde após a análise para alocação dos recursos este passa a fazer parte do projeto.

O Objeto refere-se à matéria-prima em que a atividade é dirigida e que é moldada e transformada em resultados, com a ajuda dos artefatos mediadores (classe Instrumento). $\mathrm{O}$ objeto representa a natureza objetiva da atividade humana e permite que os indivíduos controlem seus próprios motivos e comportamento ao realizar a atividade [Engeström 2014]. A atividade humana é direcionada à satisfação de determinados objetivos. Em razão disso, o termo objetivo pode ser entendido no lugar de objeto.

A Comunidade representa os indivíduos e/ou subgrupos que compartilham o mesmo objeto do sujeito. A comunidade situa a atividade em estudo dentro do contexto sociocultural daqueles sujeitos que compartilham o mesmo objeto da atividade. $\mathrm{O}$ relacionamento entre os sujeitos e a comunidade é mediado por regras e divisão do trabalho. A divisão do trabalho, classe DivisaodoTrabalho, refere-se tanto a divisão horizontal de tarefas entre os membros da comunidade quanto na divisão vertical de poder e status. E as Regras representam os regulamentos explícitos e implícitos, normas e convenções que restringem as ações e interações dentro do sistema de atividade [Engeström 2014].

\subsection{Recomendação de Riscos}

Um dos diferenciais do modelo Átropos em relação aos trabalhos relacionados, diz respeito à recomendação de riscos ao projeto. A partir da análise dos históricos de projetos passados, o modelo busca riscos que tenham sido identificados e recomenda para um novo projeto que se inicia, funcionalidade esta que remete a primeira questão de pesquisa desta proposta. A Figura 3 apresenta o fluxo para recomendação de riscos e respostas para mitigação a partir de um novo projeto.

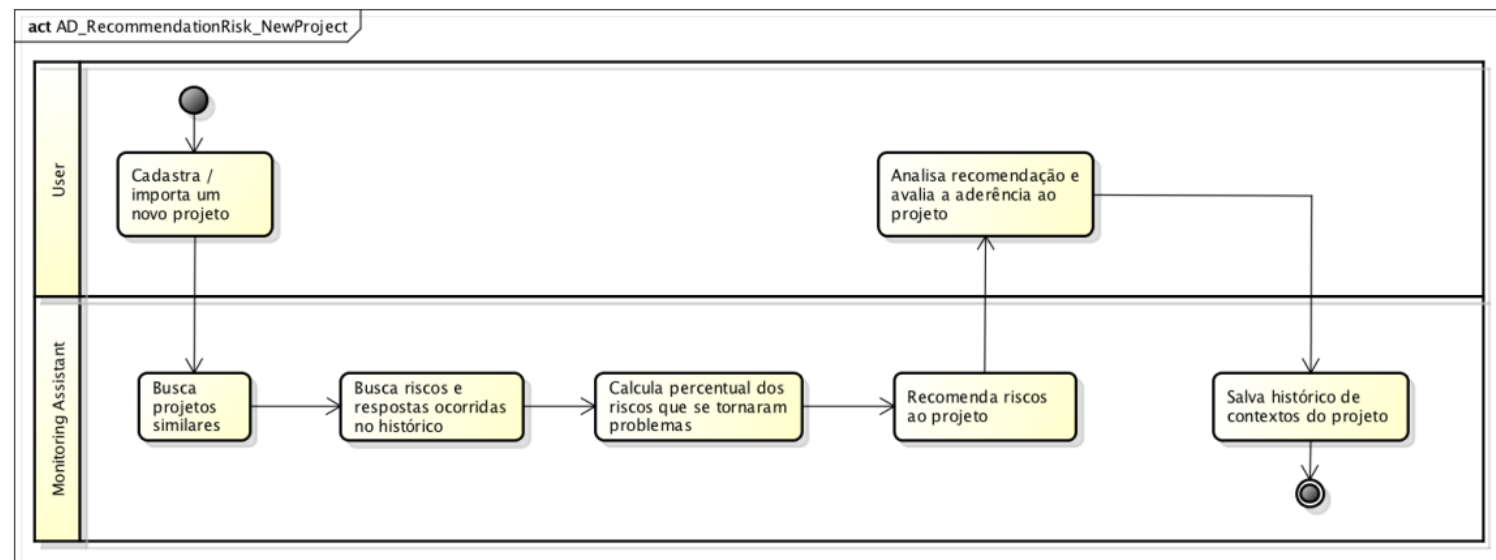

Figura 3: Fluxo de Recomendação de Riscos em um Projeto 
A seguir é apresentado o detalhamento das atividades que compõem o fluxo:

- Cadastra / importa um novo projeto: o fluxo é iniciado a partir de um cadastramento de um novo projeto ou a importação dos dados de uma base de dados existente, contendo as seguintes informações para caracterizar o projeto, tamanho do projeto, período planejado de execução, ramo de atividade em que o projeto será executado, descrição do projeto, descrição do escopo, situação atual, data da última atualização, orçamento planejado, orçamento executado, além das atividades ou histórias de usuário caso existam;

- Busca projetos similares: após o cadastramento de um novo projeto, o bot de monitoramento identifica este evento e inicia o processo para recomendação, inicialmente identificando os projetos similares, através de características como ramo do projeto, tamanho e análise sobre as tecnologias ou conhecimentos que compõem o projeto, que podem auxiliar com informações para o novo projeto;

- Busca riscos e respostas ocorridas no histórico: com os projetos similares identificados, então é realizada uma análise nos históricos destes projetos a fim de identificar os riscos mapeados e as respostas para mitigação já utilizadas;

- Calcula percentual dos riscos que se tornaram problemas: a quantidade de riscos que se tornou problema nos projetos e seu percentual é uma informação apresentada aos gestores com o objetivo de analisar os riscos que realmente têm se concretizado nos projetos, para que estes riscos sejam avaliados com maior atenção na seleção das estratégias de respostas;

- Recomenda riscos ao projeto: após o término da análise sobre os históricos dos projetos, então os riscos identificados juntamente com as respostas de mitigação utilizadas nestes riscos são retornados ao usuário para sua avaliação;

- Analisa recomendação e avalia aderência ao projeto: com todos os riscos recomendados, o usuário pode avaliar os riscos que ele deseja manter no projeto ou pode marcar para ignorar a recomendação;

- Salva histórico de contextos do projeto: ao final da análise do usuário sobre os riscos recomendados, são salvos os dados no histórico de contextos do novo projeto iniciado.

As interações realizadas pelos gestores e equipes técnicas ocorrem fazendo uso do protótipo, que será detalhado na próxima seção. Este módulo corresponde a uma aplicação híbrida multi-plataformas, que tem por objetivo apoiar o modelo proposto através do uso de dispositivos móveis.

\subsection{Protótipo}

A identificação dos riscos poderá ser realizada a qualquer momento de forma colaborativa por todos os stakeholders. Este processo para gestão dos riscos é iniciado pela recomendação de riscos ao projeto. Através de uma análise nos históricos dos projetos, os riscos identificados de projetos similares são apresentados ao usuário para sua análise, conforme mostra a Figura 4. Nesta etapa o usuário poderá consultar os 
riscos que foram recomendados, com o detalhamento da descrição e o percentual de ocorrências em que este risco virou um problema. Como por exemplo, se um determinado risco foi identificado em 10 projetos diferentes, e acabou ocorrendo em 4 destes projetos, o percentual irá apresentar os $40 \%$ de ocorrência. Com base nestas informações o usuário poderá aceitar o risco, e então este é atribuído ao projeto ou rejeitar a recomendação do risco.

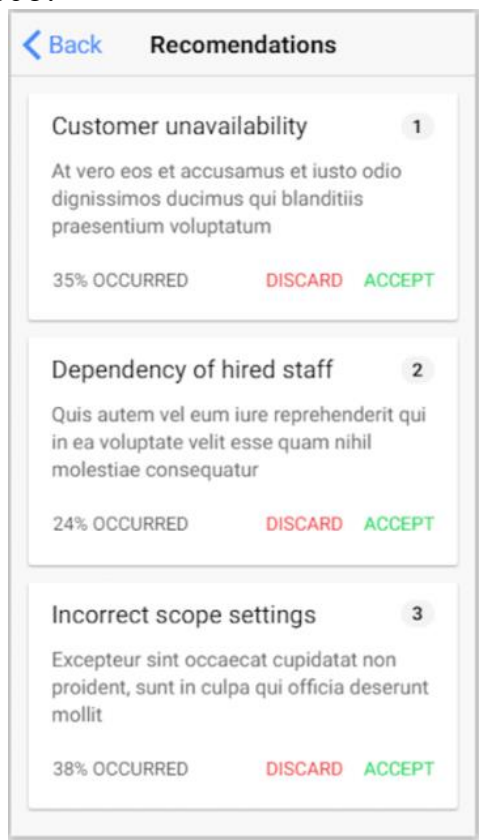

Figura 4: Avaliação dos Riscos Recomendados

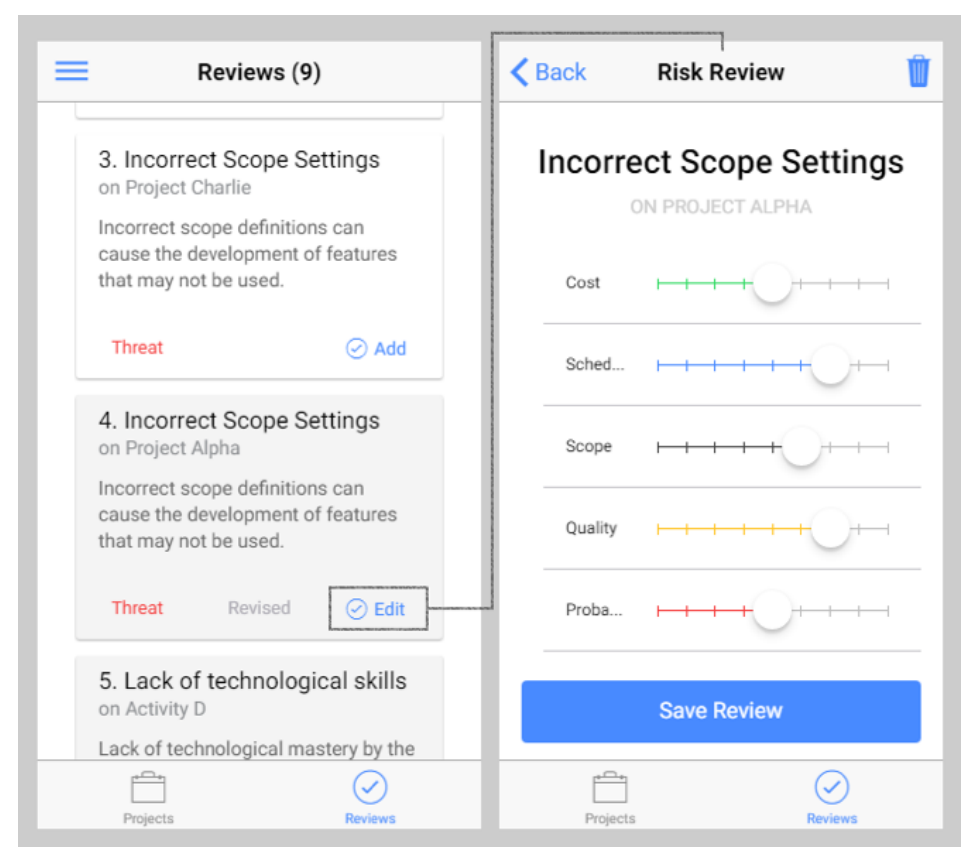

Figura 5. Análise do Risco

A avaliação dos riscos pode ser realizada por qualquer stakeholder, uma vez que o mesmo esteja vinculado como recurso ao projeto onde o risco foi identificado. Esta interação ocorre em formato de questionário, contendo valores pré-determinados de 
custo, cronograma, escopo, qualidade e probabilidade de ocorrência, onde o usuário deverá optar pela opção apropriada de acordo com seu entendimento, conforme exibido na Figura 5.

Os parâmetros de escolha do questionário são representados por uma tabela de referências. Cada referência acompanha sua escala numérica de peso, sendo: muito baixo: 0,1, baixo: 0,3, médio: 0,5, alto: 0,7 e muito alto: 0,9 . Esta escala denota o mérito de impacto do risco em cada área. A Figura 6 apresenta exemplos de itens da tabela de referência previamente cadastrada.

\begin{tabular}{|c|c|c|}
\hline descricao & tipo & peso \\
\hline Impacto insignificante no custo & CUSTO & 0.1 \\
\hline Impacto no custo em até $1 \mathrm{~K}$ & CUSTO & 0.3 \\
\hline Impacto no custo entre $1 \mathrm{~K}$ e $3 \mathrm{~K}$ & CUSTO & 0.5 \\
\hline Impacto no custo entre $3 \mathrm{~K}$ e $5 \mathrm{~K}$ & CUSTO & 0.7 \\
\hline Impacto no custo maior que $5 \mathrm{~K}$ & CUSTO & 0.9 \\
\hline Impacto insignificante no cronograma & CRONOGRAMA & 0.1 \\
\hline Impacto de menos de 1 dia no cronograma & CRONOGRAMA & 0.3 \\
\hline Impacto de 1 a 3 dias no cronograma & CRONOGRAMA & 0.5 \\
\hline Impacto de 3 a 5 dias no cronograma & CRONOGRAMA & 0.7 \\
\hline Impacto de mais de 5 dias no cronograma & CRONOGRAMA & 0.9 \\
\hline
\end{tabular}

Figura 6. Valores de Referência da Avaliação de Riscos

A Tabela 3 tem por objetivo apoiar no entendimento quanto aos métodos aplicados para a obtenção dos resultados durante as próximas etapas. Durante a leitura entende-se apropriado consultar esta tabela, uma vez que todos os dados apresentados nas figuras estão aqui detalhados.

Tabela 3. Variáveis e Cálculos da Análise Quantitativa

\begin{tabular}{|l|l|}
\hline Variável & Cálculo \\
\hline $\begin{array}{l}\text { Impacto Consolidado do } \\
\text { Risco }\end{array}$ & $\begin{array}{l}\text { Maior valor entre os fatores de custo, cronograma, escopo e } \\
\text { qualidade. }\end{array}$ \\
\hline Prioridade do risco & $\begin{array}{l}\text { Baixo: grau de qualificação até } 0,3 . \\
\text { Médio: grau de qualificação entre } 0,3 \text { e } 0,7 . \\
\text { Alto: grau de qualificação acima de 0,7. }\end{array}$ \\
\hline $\begin{array}{l}\text { Grau de Qualificação do } \\
\text { Risco }\end{array}$ & $\begin{array}{l}\text { Impacto consolidado multiplicado pela probabilidade de } \\
\text { ocorrência. }\end{array}$ \\
\hline R\$ Impacto & Valor do projeto multiplicado pelo custo. \\
\hline R\$ Esperado & R\$ Impacto multiplicado pela probabilidade. \\
\hline Probabilidade (Prob.) & Média do percentual da probabilidade do risco. \\
\hline Peso Geral & Soma do grau de qualificação dos riscos do projeto. \\
\hline $\begin{array}{l}\text { Grau de Qualificação do } \\
\text { Projeto }\end{array}$ & Maior grau de qualificação entre os riscos do projeto. \\
\hline Risco Geral do Projeto & $\begin{array}{l}\text { Peso geral do projeto dividido pela quantidade de riscos do } \\
\text { projeto dividido pelo grau de qualificação do projeto }\end{array}$ \\
\hline Melhor Caso & Valor base - soma do impacto dos riscos de oportunidade. \\
\hline Valor Base & Valor total do projeto. \\
\hline Valor Esperado & Impacto multiplicado pela média de probabilidade do risco. \\
\hline Pior Caso & Valor base + soma do impacto dos riscos de ameaça. \\
\hline
\end{tabular}

Um risco poderá receber diversas análises, de diferentes usuários. Um mesmo risco pode ser vinculado a mais de um projeto ou a mais de uma atividade, o que possibilita avaliações distintas do risco de acordo com o projeto ou atividade. Esta abordagem contribui para a reutilização de um mesmo risco em projetos e atividades futuras.

iSys: Revista Brasileira de Sistemas de Informação (isys: Brazilian Journal of Information Systems) http://seer.unirio.br/index.php/isys/ 
A partir da média de análises dos fatores de impacto (custo, cronograma, escopo e qualidade) é mensurado impacto consolidado do risco. O impacto consolidado é composto pelo maior valor entre os fatores de impacto. Por exemplo, se um risco recebe avaliação 0,7 para custo, 0,5 para cronograma, 0,1 para escopo e 0,3 para qualidade, o seu grau de impacto consolidado será considerado 0,7. Esta informação denota em qual área o risco possui maior relevância, sendo também utilizado para compor os cálculos das etapas seguintes.

Para qualificar o risco quanto à sua prioridade, é necessário calcular o seu grau de qualificação. Esta informação é obtida através da multiplicação do impacto consolidado pela probabilidade de ocorrência do risco.

Com o objetivo de apresentar uma visão gerencial do modelo, os riscos são agrupados por projeto. A Figura 7 mostra um projeto, seus respectivos riscos e a análise qualitativa dos mesmos. Os valores apresentados nesta visão são compostos pela média das análises efetuadas dos riscos.

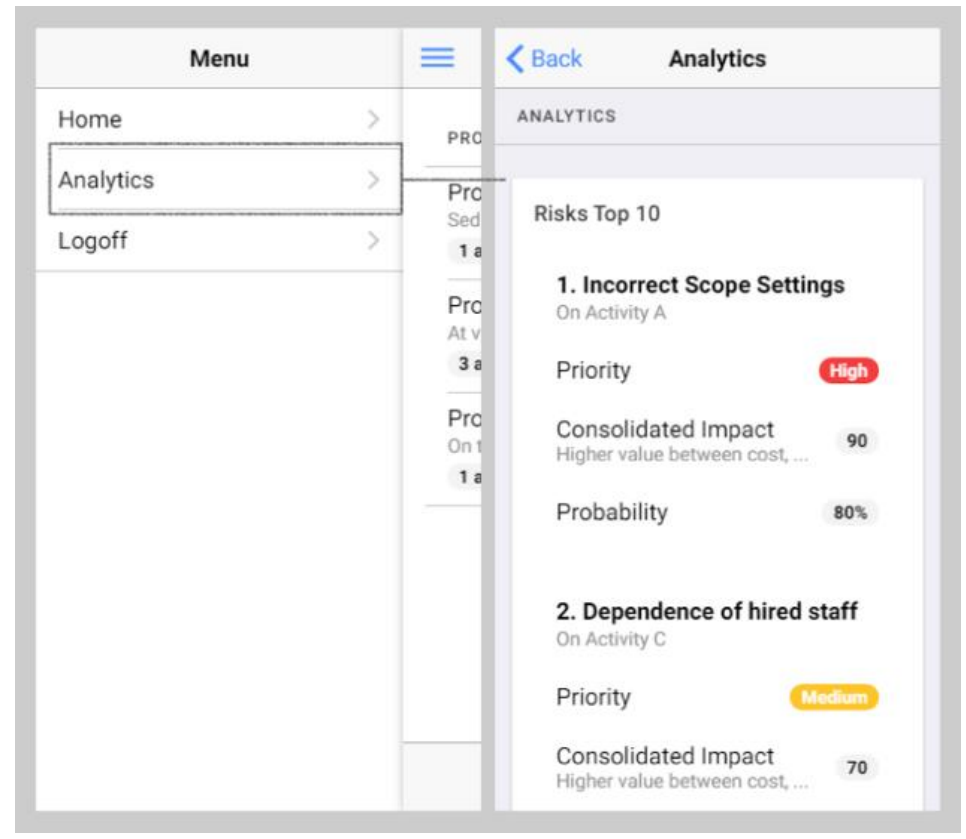

Figura 7. Análise Qualitativa do Risco por Projeto

A análise qualitativa oferece benefícios consideráveis no entendimento das futuras incertezas do projeto, evidenciando os riscos de maior prioridade e salientando em qual área o risco tem maior impacto dentro do projeto. Entretanto, abordar somente a análise qualitativa pode não oferecer uma visão precisa do grau que os riscos identificados impactam nos objetivos do projeto [Joia et al. 2013].

A análise quantitativa oferece uma visão mais objetiva em relação à análise qualitativa, possibilitando assim uma avaliação mais clara dos riscos do projeto para os gestores. O método utilizado para quantificar os riscos neste modelo é denominado priorização por valor esperado [Joia et al. 2013], que tem por objetivo determinar o valor real do que se espera que aconteça. Nesta etapa, os custos das atividades dos projetos são relacionados com as análises dos riscos dos mesmos. A Figura 8 apresenta os riscos do projeto e seus valores. 


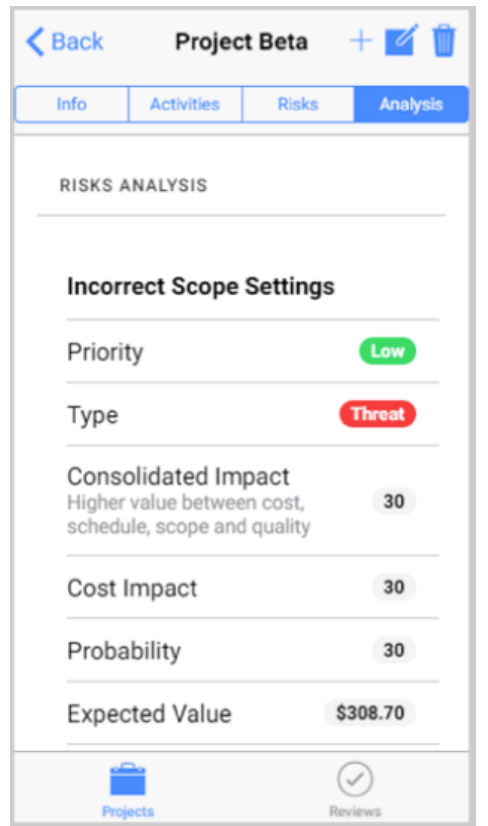

Figura 8. Análise Quantitativa dos Riscos por Projeto

Os riscos categorizados como tipo ameaça, contribuirão para aumentar o preço final do projeto e os riscos de oportunidade surtirão efeito contrário. Este enfoque permite a quantificação monetária dos dados, o que faz com que os resultados obtidos ao final do processo facilitem a tomada de decisão por parte da gestão do projeto. A Figura 9 apresenta os valores esperados do projeto.

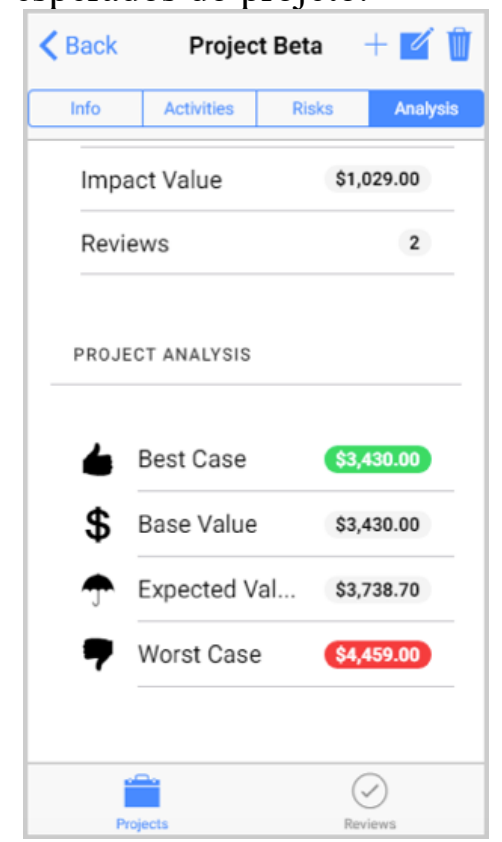

Figura 9. Análise Quantitativa dos Riscos por Projeto - Valores Esperados

\subsection{Arquitetura}

O diagrama de classes apresenta a arquitetura da aplicação. Neste diagrama foram omitidos seus métodos, instruções e seus atributos com o objetivo de demonstrar de 
maneira simplificada apenas o relacionamento entre as classes da solução. Através do modelo do diagrama de classes observa-se a classe Risco sendo relacionada com as classes Projeto, Demanda (atividade), RiscoProjeto, RiscoDemanda e RiscoAnalise, entre outras. Um risco pode ser visualizado em um projeto, em uma atividade (demanda) ou individualmente, contendo apenas suas informações básicas e suas dependências, como análises, categorias etc. A Figura 10 apresenta a arquitetura mencionada.

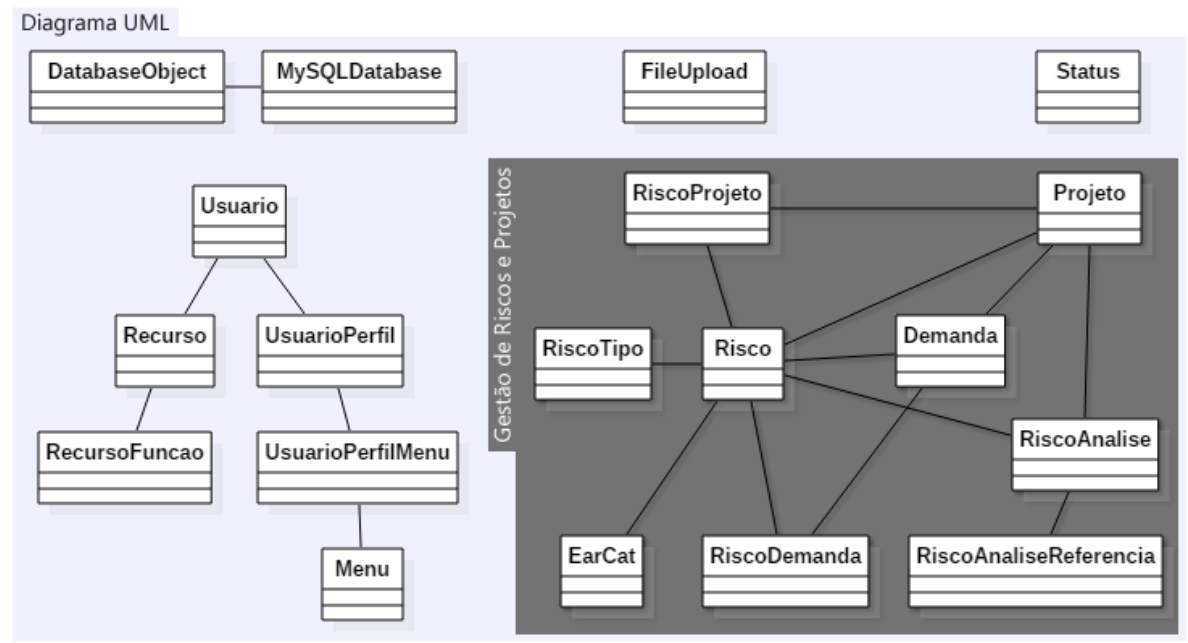

Figura 10. Diagrama de Classes da Aplicação

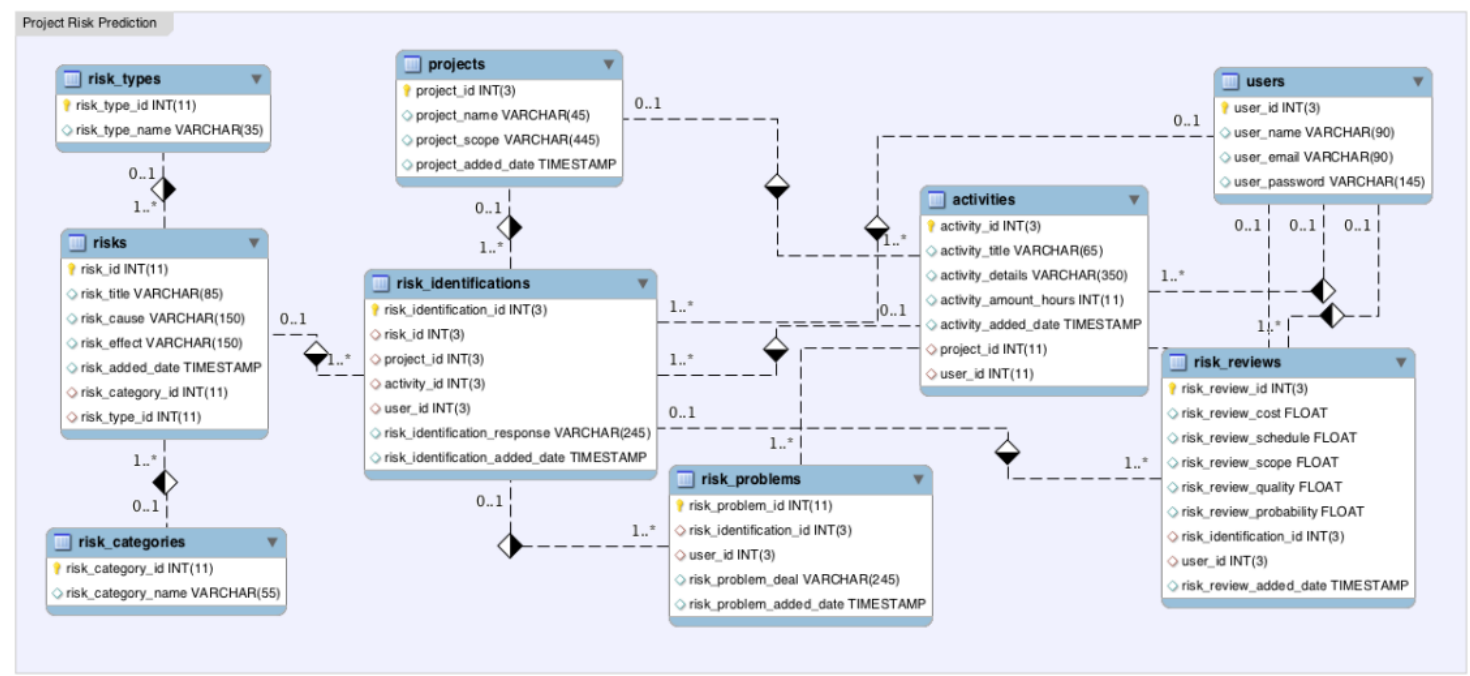

Figura 11. Modelo Entidade Relacionamento

Nesta visão é possível observar as classes do modelo de gerenciamento de riscos na parte inferior direita da figura, a qual recebe destaque por trazer maior relevância quanto ao entendimento da arquitetura. As classes RiscoDemanda e RiscoProjeto tornam possível a reutilização dos riscos em projetos e atividades futuras.

O modelo "Entidade Relacional" (ER) do banco de dados foi projetado para comportar tanto informações relevantes ao gerenciamento dos riscos quanto informações dos projetos. Deste modo é possível implementar o gerenciamento de riscos a partir do padrão especificado pelo guia $\mathrm{PMBoK}$, considerando o escopo, cronograma e as informações referentes ao custo dos projetos. A Figura 11 exibe o isys: Revista Brasileira de Sistemas de Informação (isys: Brazilian Journal of Information Systems) http://seer.unirio.br/index.php/isys/ 
modelo ER do banco de dados. Mais uma vez, as entidades mais relevantes são apresentadas de maneira detalhada.

As principais entidades do modelo são as tabelas projeto, risco, risco_projeto e risco_analise. A tabela risco_analise acomoda as avaliações dos riscos realizadas pelos usuários, esta tabela pode conter inúmeras avaliações para cada risco. A entidade risco_projeto permite a relação de diversos projetos com diversos riscos, o que possibilita a visão de impacto de um determinado risco em projetos distintos. As demais entidades apoiam o gerenciamento mínimo do projeto e o gerenciamento de riscos. A estrutura analítica de riscos com base na teoria da atividade é representada pela tabela categoria através de sua configuração.

\section{Avaliação e Resultados}

Um estudo de caso foi aplicado com o objetivo de avaliar as recomendações de riscos realizadas pelo modelo Átropos e seu uso por uma equipe que estava atuando nos projetos de forma distribuída. Esta execução, procurou validar o uso do Átropos e sua aderência para a gestão dos riscos e recomendações aos projetos em andamento.

\subsection{Configuração do Ambiente}

Um servidor hospedado em nuvem foi utilizado para suportar o funcionamento da aplicação em dispositivos móveis. Neste servidor, uma API (Application Programming Interface) foi disponibilizada via Restful (Representational State Transfer) para possibilitar a integração entre os smartphones dos usuários e o banco de dados da aplicação. $\mathrm{O}$ aplicativo cliente foi instalado na plataforma Android. Cada profissional obteve acesso ao software do protótipo através de um smartphone, onde puderam realizar toda a gestão dos riscos dos projetos, além de analisarem as recomendações realizadas pelo Átropos.

\subsection{Recomendação}

A listagem dos projetos e riscos foi obtida em formato de planilha Excel. Um script foi escrito para processar esta planilha e transportar as suas informações para um banco de dados relacional utilizado pelo modelo. $\mathrm{O}$ uso dos dados históricos dos projetos, serviu como entrada para o modelo pesquisar projetos similares e permitir a recomendação de riscos com base neste histórico para os novos projetos.

Posteriormente, um outro script, classificou os projetos. Esta classificação foi realizada através do uso da Google Natural Language API (GAPI). A GAPI fornece recursos para a análise de textos não estruturados. Dentre estes recursos está a classificação de conteúdos. A Classificação de conteúdo analisa um documento e retorna uma lista de categorias de conteúdo que se aplicam ao texto encontrado neste documento [GOOGLE 2019]. Para exemplificar, a Tabela 4 mostra a classificação efetuada utilizando a base do histórico contendo 463 projetos. São exibidas categorias que contém 5 ou mais projetos vinculados.

Posteriormente o mesmo processo de classificação foi aplicado nos projetos cadastrados através do protótipo durante a aplicação do estudo de caso. O objetivo desta etapa foi realizar uma análise de similaridade entre os novos projetos e o histórico, de acordo com sua respectiva área de conhecimento e tamanho. A classificação de tamanho 
dos projetos teve por referência a quantidade de tempo necessária para execução. Cada projeto foi classificado em uma das três categorias de tamanho: pequeno (até 300hs), médio (até $1000 \mathrm{hs}$ ) e grande (acima de $1000 \mathrm{hs}$ ). A Tabela 5 mostra a classificação dos projetos cadastrados, com a quantidade de projetos similares identificados e os riscos recomendados a partir do histórico. Os nomes dos projetos foram ocultados por questões de privacidade de informação.

Tabela 4. Classificação do Histórico de Projetos

\begin{tabular}{|l|c|}
\hline Categoria & Quantidade de Projetos \\
\hline /Negócios e Indústria & 62 \\
\hline /Finanças & 42 \\
\hline /Computadores e Eletrônicos & 28 \\
\hline /Finanças/Contabilidade e Auditoria & 13 \\
\hline /Finanças/Crédito e Empréstimo & 10 \\
\hline /Computadores e Eletrônicos/Software & 8 \\
\hline /Arte e Entretenimento & 6 \\
\hline /Comercial e industrial/Operações comerciais & 6 \\
\hline /Computadores e Eletrônicos/ Tecnologia Empresarial & 6 \\
\hline /Finanças/Bancário & 6 \\
\hline
\end{tabular}

Tabela 5. Classificação dos Projetos Cadastrados

\begin{tabular}{|l|l|l|c|c|}
\hline Projeto & Tamanho & \multicolumn{1}{|c|}{ Categoria } & $\begin{array}{c}\text { Qtd de Projetos } \\
\text { Similares }\end{array}$ & $\begin{array}{c}\text { Qtd Riscos } \\
\text { Recomendados }\end{array}$ \\
\hline Projeto A & Médio & /Negócios e Indústria & 21 & 12 \\
\hline Projeto B & Médio & /Negócios e Indústria & 21 & 12 \\
\hline Projeto C & Médio & /Artes e Entretenimento & 1 & 5 \\
\hline Projeto D & Médio & /Leis e Governo & 0 & 0 \\
\hline Projeto E & Médio & - & - & - \\
\hline Projeto F & Pequeno & /Negócios e Indústria & 9 & 7 \\
\hline Projeto G & Pequeno & /Finanças & 13 & 0 \\
\hline & Grande & /Computadores e & 0 & - \\
\hline Projeto H & & $\begin{array}{l}\text { Eletrônicos/Software/Negócios e } \\
\text { Software de Produtividade }\end{array}$ & & 5 \\
\hline Projeto I & Pequeno & - & - & 5 \\
\hline Projeto J & Pequeno & /Negócios e Indústria & 9 & 9 \\
\hline Projeto K & Pequeno & /Negócios e Indústria & 9 & \\
\hline
\end{tabular}

Para os Projetos E e I não foram identificados outros projetos similares na base histórica. Esse fato ocorreu porque os projetos não estavam classificados nas categorias que constavam no histórico. Já os projetos $\mathrm{D}$ e $\mathrm{H}$, não foram encontrados projetos com as mesmas características para gerar a recomendação dos riscos. Para os demais projetos, o algoritmo identificou os riscos que constavam no histórico para permitir a recomendação aos novos projetos. Para os projetos cadastrados em que foram encontrados mais de um projeto similar na base histórica, os riscos foram agrupados, para não gerar a recomendação do mesmo risco mais de uma vez.

Através da análise de similaridade dos projetos que constam no histórico, são identificados possíveis riscos ao novo projeto. A equação (1) calcula a similaridade dos projetos (Sim). Para calcular, é realizada uma consulta a todos os projetos que constam no histórico $(\mathrm{Ph})$, onde é realizado um somatório da similaridade de cada variável que consta no histórico (vh) com a variável do projeto em execução, multiplicando pelo 
peso (w) que foi atribuído para cada variável. Para os projetos similares os riscos são carregados e apresentados como recomendação relacionada ao novo projeto.

$$
\operatorname{Sim}=P h_{0 . . n}\left(\sum_{1 . .7}\left(v h_{z} * w_{z}\right)\right)
$$

Após a recomendação dos riscos ao novo projeto, os riscos devem ser analisados e o responsável pode aceitar ou rejeitar o risco para o novo projeto (Figura 4). Os riscos que forem aceitos passam a compor o projeto, já os riscos que forem rejeitados, estes são excluídos de forma lógica, para que haja um acompanhamento ao longo do projeto. A Tabela 6 apresenta a quantidade de riscos que foram apropriados a partir da recomendação.

Tabela 6. Riscos Apropriados da Recomendação

\begin{tabular}{|l|c|c|c|}
\hline Projeto & $\begin{array}{c}\text { Qtd Riscos } \\
\text { Recomendados }\end{array}$ & $\begin{array}{c}\text { Qtd de Riscos } \\
\text { Apropriados }\end{array}$ & \% Apropriação \\
\hline Projeto A & 12 & 10 & $83,33 \%$ \\
\hline Projeto B & 12 & 10 & $83,33 \%$ \\
\hline Projeto C & 5 & 3 & $60 \%$ \\
\hline Projeto F & 5 & 5 & $100 \%$ \\
\hline Projeto G & 7 & 6 & $85,71 \%$ \\
\hline Projeto J & 5 & 3 & $60 \%$ \\
\hline Projeto K & 5 & 3 & $60 \%$ \\
\hline
\end{tabular}

Após análise dos stakeholders sobre os riscos que foram recomendados para os 7 projetos cadastrados, foram aprovados uma média de $76,05 \%$ dos riscos para os novos projetos. A média apresentada de apropriação dos riscos para os novos projetos, demonstra a aceitação do modelo Átropos para recomendação dos riscos, visando dar maiores informações para os gestores desde o início do projeto.

\subsection{Análise Durante a Execução dos Projetos}

Um estudo de caso foi conduzido em uma equipe, composta por 5 profissionais, de desenvolvimento distribuído de software para validar o modelo Átropos quanto a identificação de forma colaborativa pela equipe e condução dos riscos durante todo o ciclo de vida do projeto. A equipe era composta por 1 gerente de projetos e 1 programador, atuando em São Paulo, e 1 programador, 1 analista de sistemas e um 1 analista de suporte atuando no Rio Grande do Sul. A Tabela 7 mostra as características dos profissionais que participaram do estudo de caso. Durante este período foram cadastradas 59 atividades e 13 riscos. Foram realizadas 19 análises destes riscos, identificados 5 problemas em projetos e 3 problemas em atividades de projeto.

Tabela 7. Perfis dos Profissionais Envolvidos no Estudo de Caso

\begin{tabular}{|l|l|l|l|l|}
\hline Nome & Papel & $\begin{array}{l}\text { Nível de } \\
\text { Experiência (anos) }\end{array}$ & Localização & Duração \\
\hline Profissional A & Analista de Sistemas & Sênior (10+) & RS & 4 Semanas \\
\hline Profissional B & Gerente de Projetos & Sênior (10+) & São Paulo & 4 Semanas \\
\hline Profissional C & Programador & Sênior (10+) & RS & 3 Semanas \\
\hline Profissional D & Programador & Pleno (5+) & São Paulo & 2 Semanas \\
\hline Profissional E & Analista de Suporte & Pleno (5+) & RS & 4 Semanas \\
\hline
\end{tabular}


Após a recepção das informações indicadas, o sistema efetuou a categorização dos riscos através de uma estrutura analítica de riscos (EAR). Esta EAR é baseada na teoria da atividade. Os elementos da teoria da atividade são utilizados com o objetivo de criar os agrupamentos de riscos, onde a análise de resposta aos riscos passa a considerar que em determinados casos uma resposta possa endereçar mais de um risco, pois a causa pode ser a mesma. A categorização ainda propicia uma visão aos gestores de áreas que possuem a maior probabilidade de impactar no projeto, permitindo priorizar os riscos que devem ser mitigados. Os riscos relacionados aos indivíduos tiveram maior quantidade de ocorrência, como mostra a Figura 12.

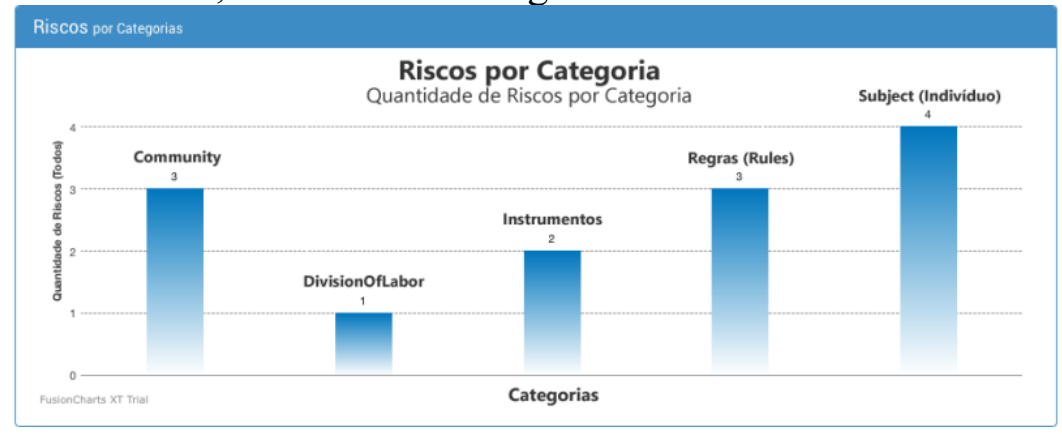

Figura 12. Riscos por Categorias

Os riscos foram distribuídos entre os projetos de maneira semelhante. Não houve projetos com quantidade elevada de riscos quando comparado aos demais. A Figura 13 imagem (a) apresenta estes dados.

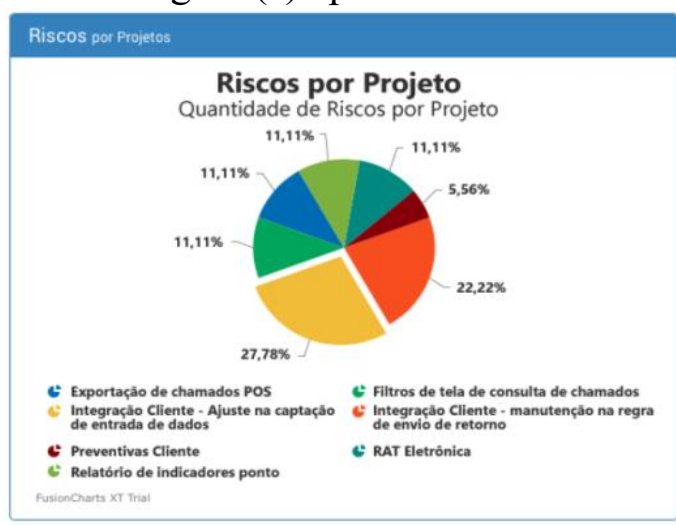

(a)

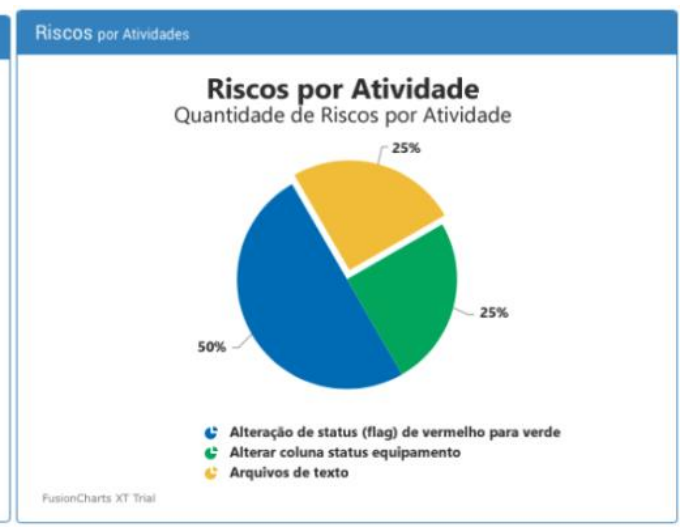

(b)

Figura 13. Riscos por Projetos e Atividades

A amostragem de riscos por atividades foi menor, caracterizando poucos riscos relacionados a atividades específicas, quando comparadas a projetos, apresentados na Figura 13 (b).

Quatro projetos receberam marcação de problemas durante a execução, e um deles, o projeto Exportação de chamados POS, recebeu $40 \%$ destes problemas. Os problemas mais recorrentes foram: Dependência de Equipe Terceira e Redefinições Constantes de Prioridades. A Figura 14, imagem (a) mostra os problemas agrupados por projetos. 


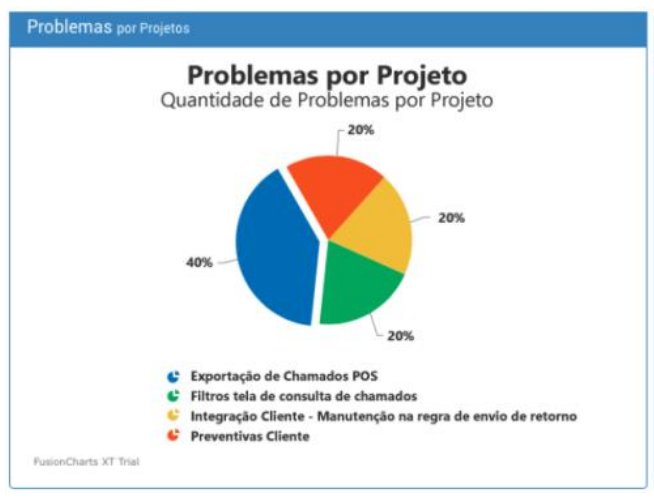

(a)

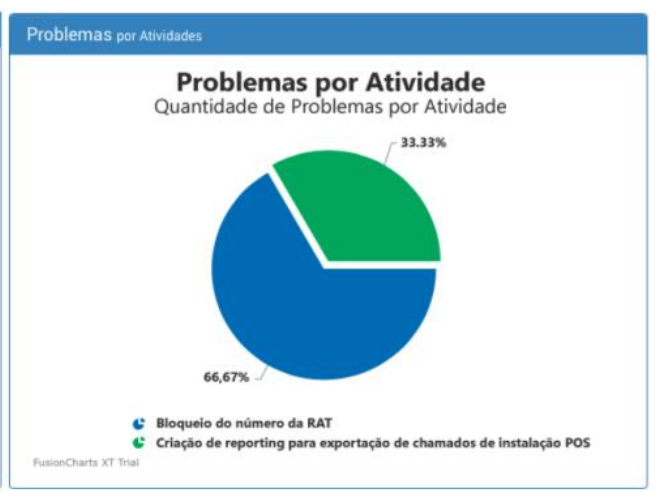

(b)

Figura 14. Problemas por Projetos e Atividade

Duas atividades receberam marcação de problemas durante a execução, destaque para a atividade Criação de Reporting para Exportação de Chamados de Instalação POS, a Figura 14 imagem (b) mostra os problemas agrupados por atividades.

Os riscos mais críticos do estudo de caso, bem como o grau de impacto e a prioridade de cada um deles, são exibidos através de uma lista, auxiliando as equipes no entendimento das prioridades. O risco Dependência de equipe terceira recebeu destaque, recebendo alta prioridade de acordo com as análises realizadas. Estes dados são mostrados na Figura 15.

\begin{tabular}{|llll|}
\hline Riscos Mais Criticos & & & \\
\hline Titulo & Projeto & Grau & Prior. \\
\hline Dependência de equipe terceira & Exportação de chamados P... & 0.81 & Alto \\
\hline Dependência de equipe terceira & Integração Cliente Banri... & 0.81 & Alto \\
\hline Redefiniçōes constantes de prioridades & Preventivas Cliente Saqu... & 0.63 & Medio \\
\hline Mudanças constantes de escopo & Integração Cobra - Manut... & 0.63 & Medio \\
\hline Mudanças constantes de escopo & Integração Cliente Banri... & 0.63 & Medio \\
\hline Ausência de membro da equipe & Integração Cliente Banri... & 0.49 & Medio \\
\hline Mudanças constantes de escopo & Relatório de Indicadores.... & 0.49 & Medio \\
\hline Redefinições constantes de prioridades & Integração Cliente Banri... & 0.49 & Medio \\
\hline Definiçōes incorretas de escopo & Integração Cobra - Manut... & 0.49 & Medio \\
\hline Interrupçōes do trabalho da equipe & RAT Eletrônica & 0.45 & Medio \\
\hline
\end{tabular}

Figura 15. Riscos Mais Críticos (Riscos Priorizados)

Para exemplificar a visão dos valores esperados de projeto, foi selecionado o projeto Integração cliente - Manutenção da regra de envio de retorno, que teve seu valor base (custo) estimado inicialmente em R\$ 528,00. Após a aplicação do modelo proposto, com a devida identificação e análise dos seus riscos, foi possível calcular o seu valor esperado, que resultou em $\mathrm{R} \$ 1.140,48$. Se todos os riscos identificados para este projeto ocorressem, seu valor seria elevado para $\mathrm{R} \$ 1.584,00$, conforme mostra a Figura 16. 


\begin{tabular}{|cccc|}
\hline Análise Quantitativa valores esperados & & \\
\hline Melhor Caso 9 & Valor Base 4 & Valor Esperado 9 & Pior Caso 9 \\
\hline $\mathrm{R} \$ 528.00$ & $\mathrm{R} \$ 528.00$ & $\mathrm{R} \$ 1,140.48$ & $\mathrm{R} \$ 1,584.00$ \\
\hline
\end{tabular}

Figura 16. Valores Esperados do Projeto

Este estudo de caso mostrou a importância do modelo Átropos para a gestão de riscos em projetos de software distribuídos. Os resultados obtidos ao final do processo contribuíram para formar dados consolidados e objetivos, esclarecendo o impacto dos riscos nos projetos. Entende-se que a gestão de riscos é um processo contínuo, e a utilização deste modelo ao longo do tempo, contribui para o crescimento de sua base de dados. Uma maior quantidade de amostragens torna as informações mais confiáveis, o que favorece no entendimento das incertezas para os gestores de projetos.

\subsection{Resultados e Respostas as Questões de Pesquisa}

A partir da análise do estudo de caso, percebe-se as lacunas existentes quanto a gestão de riscos em projetos. Com o uso do modelo Átropos através do protótipo desenvolvido, as equipes conseguiram acompanhar e analisar os riscos, quantificando seu impacto em relação ao projeto de forma colaborativa, recebendo recomendações no início de cada projeto.

O estudo de caso aplicado, teve um caráter de avaliação da hipótese elaborada a partir das questões de pesquisa. As questões de pesquisa foram elaboradas com o objetivo de validar o uso do modelo Átropos em duas dimensões: (i) recomendação de riscos a projetos similares; (ii) identificação e condução dos riscos considerando equipes distribuídas, permitindo seu uso de forma colaborativa. Neste sentido, os resultados e evidências apresentadas demonstram a aderência do modelo Átropos para a gestão proativa dos riscos em projetos.

O principal objetivo do Átropos é recomendar riscos considerando as características dos projetos, além de permitir o acompanhamento de todo o ciclo de vida dos riscos ao longo do projeto. A primeira questão de pesquisa apresentada (RQ1), questionou se as recomendações realizadas pelo modelo seriam apropriadas para o novo projeto, através de uma análise da equipe que estava desenvolvendo os projetos. Já a segunda questão de pesquisa (RQ2), procurou responder se o modelo auxilia as equipes na identificação colaborativa dos riscos nos projetos.

Assim sendo, para responder a RQ1, conclui-se através da aplicação do estudo de caso descrito, como verdadeira a hipótese inicialmente elaborada, de que os históricos de projetos possam ser utilizados para gerar recomendações de riscos aos projetos. Com uma taxa média de $76,05 \%$ de aprovação dos riscos, que foram recomendados ao projeto, por parte dos especialistas, o modelo Átropos se mostrou aderente a recomendação de riscos. Ao se considerar as características de cada projeto para a recomendação, as informações que são recomendadas pelo modelo para os projetos, tornam-se cada vez mais assertivas, pois são consideradas um conjunto de variáveis que são parametrizáveis no modelo para serem geradas as novas recomendações. Desta forma, os gestores ao iniciarem um novo projeto terão um conjunto maior de informações aderentes ao projeto em execução, proporcionando um melhor planejamento.

iSys: Revista Brasileira de Sistemas de Informação (iSys: Brazilian Journal of Information Systems) http://seer.unirio.br/index.php/isys/ 
Quanto a RQ2, durante o período de acompanhamento dos projetos no estudo de caso foram cadastradas 59 atividades e 13 riscos. Além de cadastrados, os riscos foram analisados, de forma colaborativa, onde todos os membros da equipe puderam realizar a análise para cada risco e contribuir com conhecimento sobre os impactos no projeto. Este aspecto permitiu que a análise monetária do projeto seja mais assertiva, uma vez que um grupo maior de pessoas pode analisar o risco, enquanto que o modelo considerou todas as avaliações para gerar um resultado monetário para a contingência do projeto.

Durante a execução do estudo de caso, 5 problemas em projetos e 3 problemas em atividades foram identificados. Neste sentido, a colaboração da equipe para a gestão de riscos permitiu uma análise e visualização ampla em relação aos impactos que poderiam ocorrer nos projetos, demonstrando que o protótipo desenvolvido permitiu as equipes colaborar durante todos os processos para a gestão de riscos.

A partir da confirmação das hipóteses, o trabalho apresenta como principal contribuição científica o uso da análise de similaridade dos projetos para gerar as recomendações de riscos, considerando o contexto de cada projeto. Assim, fornecendo recomendações contextualizadas de acordo com as características de cada novo projeto, o gestor inicia com um conjunto maior de informações para que o planejamento do projeto seja mais assertivo.

A principal limitação do modelo apresentado neste estudo, está relacionado a recomendação durante a execução do projeto. Para isto, é necessário que se tenha um histórico dos contextos armazenados, assim, torna possível que a análise durante a execução do projeto seja realizada. Desta forma, com o uso contínuo do modelo, irá se armazenar o histórico dos projetos, permitindo em pesquisas futuras analisar o histórico de contextos para a recomendação dos riscos.

\section{Considerações Finais}

Conforme mencionado, a área de gestão de riscos possui atualmente um baixo investimento nas organizações de desenvolvimento de software, quando comparada com as demais áreas de engenharia de software. Em muitos casos a gestão de riscos se resume apenas em uma padronizada adição de um valor percentual adicionado ao custo do produto final, onde a empresa inclui um valor representativo para os riscos que possam vir a ocorrer em seus projetos [Joia et al. 2013]. Utilizando o modelo Átropos, as organizações podem mensurar as incertezas em seus projetos com um valor muito aproximado do impacto financeiro real dos riscos identificados nos mesmos, explorando o conhecimento das pessoas envolvidas nas atividades e se beneficiando de uma base de conhecimentos evolutiva.

Os resultados apresentados mostram a aplicabilidade da recomendação de riscos para novos projetos, a partir da análise de similaridade dos históricos de projetos. Assim, demonstrando o uso do histórico para gerar informações que possam contribuir para os gerentes de projetos tornarem o planejamento mais próximo do executado.

A participação de todos os integrantes das equipes nas etapas de identificação e análise de riscos proporcionou ao modelo a colaboração de todos os stakeholders, uma abordagem que não está presente em todos os trabalhos pesquisados, uma vez que normalmente a gestão do projeto é a equipe responsável por estas atividades. Este 
diferencial tornou possível a coleta de uma maior quantidade de informações durante a execução do projeto e trouxe consigo conhecimento técnico e prático sobre a importância dos riscos.

O uso de uma aplicação híbrida multi-plataformas durante as interações contribuiu para tornar o gerenciamento de riscos compatível com a realidade de projetos de software distribuídos, um método não explorado nos demais trabalhos, que garantiu uma dinâmica que favoreceu o uso do modelo de maneira amigável e natural aos usuários, uma vez que acessado pelo smartphone.

A priorização dos riscos permitiu direcionar os gestores de projetos para atuação primeiramente nos riscos mais críticos. A quantificação dos riscos, que tem como base os valores de custo de cada projeto, possibilitou análises claras aos gestores e melhor entendimento para estes sobre a importância do gerenciamento de riscos em seus projetos. A utilização contínua deste modelo permite formar uma base de informações que visa contribuir para a recomendação de riscos em projetos futuros, através do histórico de ocorrências, formando um diferencial que evolui continuamente juntamente ao ciclo de vida dos projetos.

Com base nos resultados obtidos através do estudo de caso, foram encontradas questões que podem ser melhor exploradas em trabalhos futuros. A primeira delas seria uma gestão para as estratégias de mitigação, a fim de subsidiar os gestores para a seleção da estratégia mais adequada. Além disso, o uso do modelo ao longo do tempo pode prover um histórico mais robusto de projetos, permitindo que recomendações mais assertivas de riscos sejam realizadas pelo software.

\section{Agradecimentos}

Os autores agradecem à Fundação de Amparo à Pesquisa do Estado do Rio Grande do Sul (FAPERGS), à Coordenação de Aperfeiçoamento de Pessoal de Nível Superior Brasil (CAPES) - Código de Financiamento 001, ao Conselho Nacional de Desenvolvimento Científico e Tecnológico (CNPq), ao Banco do Estado do Rio Grande do Sul (Banrisul) e à Universidade do Vale do Rio dos Sinos (Unisinos) pelo apoio ao desenvolvimento desse trabalho. Os autores reconhecem especialmente o apoio do Programa de Pós-Graduação em Computação Aplicada (PPGCA) e do Laboratório de Computação Móvel (Mobilab) da Unisinos.

\section{Referências}

Allen, David; Karanasios, Stan; Slavova Mira. (2011). Working With Activity Theory: Context, Tecnology, and Information Behavior, In: Journal of the American Society for Information Science and Technology. Doi: 10.1002/asi.21441.

Ambler, S. (2012). Agility at Scale Survey: Results from the summer 2012 DDJ State of the IT Union Survey. Disponível em: http://www.ambysoft.com/surveys/stateOfITUnion201209.html. Acesso: 22/09/2018. Audy, Jorge; Prikladnicki, Rafael. (2007). Desenvolvimento Distribuído de Software. 1 ed. Elsevier. Rio de Janeiro, Brasil, 232pp.

Barbosa, J. L. V. (2015). Ubiquitous Computing: Applications and Research Opportunities (Invited Talk). VI IEEE International Conference on Computational Intelligence and Computing Research (ICCIC), Madurai, India, p.1-8. Disponível: 
http://ieeexplore.ieee.org/stamp/stamp.jsp?tp=\&arnumber=7435625.

Acesso: 22/09/2018.

Bradner, E.; Mark, G.; Hertel, T. D. (2005). Team size and technology fit: participation, Awareness, and rapport in distributed teams, In: IEEE Transactions on Professional Communication, vol. 48, no. 1, pp. 68-77. Doi: 10.1109/TPC.2004.843299

Calefato, F.; Ebert, C. (2019). Agile Collaboration for Distributed Teams. In: IEEE Software, v. 36, p. 72-78.

Dey, Anind K. (2001). Understanding and Using Context, In: Personal and Ubiquitous Computing, Vol. 5, pp. 4-7. Doi: 10.1007/s007790170019.

Engeström, Y. (2014). Learning by expanding: An activity theoretical approach to developmental research. Ed. Cambridge University Press, 338pp.

Engeström, Y.; Sannino, A. (2011). Discursive manifestations of contradictions in organizational change efforts: A methodological framework, In: Journal of Organizational Change Management, v. 24, n. 3, p. 368-387.

Fan, Zhi-Ping; Yong-Hai, Li; Zhang, Yao. (2015). Generating project risk response strategies based on CBR: A case study, In: Expert Systems with Applications. pp 2870-2883. Doi: 10.1016/j.eswa.2014.11.034.

Fang, Chao; Marle, Franck. (2012). A simulation-based risk network model for decision support in project risk management, In: Decision Support Systems. pp 635-644. Doi: 10.1016/j.dss.2011.10.021.

Filippetto, Alexsandro; Barbosa, Jorge; Francisco, Rosemary; Klein, Amarolinda. (2016). A Project Management Model based on an Activity Theory Ontology, In: Conferência Latinoamericana de Informática.

Gerhardt, Tatiana Engel; Silveira, Denise Tolfo. (2009). "Métodos de Pesquisa", 1 ed. UFRGS, Porto Alegre, Brasil, 120pp.

Google Cloud Natural Language API Documentation | Google Cloud Natural Language API | Google Cloud ([S.d.]). Disponível: https://cloud.google.com/naturallanguage/docs/classifying-text. Acesso: 09/02/2019.

Jiang, J.; Wang, Z.; Yin, M. (2017). Research on impact of team conflict upon employee satisfaction in geographically distributed software development team. In: 3rd International Conference on Information Management (ICIM), Chengdu, pp. 136-139. Doi: 10.1109/INFOMAN.2017.7950362

Joia, L.; Soler, A.; Bernat, G.; Rabechini, R. (2013). Gerenciamento de riscos em projetos. Ed. FGV, São Paulo, Brasil, 172pp.

Knappmeyer, M.; Kaini, S. L.; Reetz, E. S.; Backer, N.; Tonies, R. (2013). Survey of Context Provisioning Middleware. In: IEEE Communications Surveys \& Tutorials. pp. 1492-1519. Doi: 10.1109/SURV.2013.010413.00207.

Leontiev, A. N. (2019). Activity, Consciousness, and Personality. [s.1.] Prentice-Hall. Disponível: http://www.marxists.org/archive/leontev/works/1978/index.htm. Acesso: 08/01/2019.

PMBOK. (2017). Project Management Institute. Um Guia do Conhecimento em Gerenciamento de Projetos (Guia PMBOK), 6th ed. Newtown Square, PA, EUA, 762pp.

Pressman, Roger S.; Maxim, Bruce R. (2016). Engenharia de Software - Uma Abordagem Profissional, 8 ed. Grupo A Educação, São Paulo, Brasil, 968pp.

Project Management Institute. (2016) Practice Standard for Project Risk Management. Newtown Square, PA, EUA, 116pp. 
Qazi, Abroon; Quigley, John; Dickson, Alex; Kirytopoulos, Konstantinos. (2016). Project Complexity and Risk Management (ProCRiM): Towards modelling project complexity driven risk paths in contruction projects, In: International Journal of Project Management. Doi: 10.1016/j.ijproman.2016.05.008.

Rosa, João H. da; Barbosa, Jorge L. V.; Ribeiro, Giovane D. (2016). ORACON: An Adaptive Model for Context Prediction, In: International Journal of Expert Systems with Applications. Pp. 56-70. Doi: 10.1016/j.eswa.2015.09.016.

Shrivastava, S. and Rathod, U. (2014). Categorization of risk factors for distributed agile projects. In: IEEE Software. Doi: 10.1016/j.infsof.2014.07.007.

Sommerville, Ian. (2015). "Engenharia de Software", 10 ed. Pearson Addison-Wesley, São Paulo, Brasil, 552pp.

Sulaman, Sardar Muhammad; Weyns, Kim; Höst, Martin. (2013). A review of research on risk analysismethodos for IT systems. roceedings of the 17th International Conference on Evaluation and Assessment in Software Engineering. Doi: $10.1145 / 2460999.2461013$

Tianyin, P. (2011). Development of software project risk management model review. In IEEE Software. Doi: 10.1109/AIMSEC.2011.6011139.

Vygotsky, L. S. (2015). A formação social da mente. 7. ed. Martins Fontes, São Paulo, Brasil, 224pp: Martins Fontes.

Yang, Kai-Cheng; Varol, Onur; Davis, Clayton A.; Ferrara, Emilio; Flammini, Alessandro; Menczer, Filippo. (2019). Arming the public artificial intelligence to counter social bots, In: Human Behavior and Emerging Technologies. Doi: 10.1002/hbe2.115.

Zhang, Yao. (2016). Selecting risk response strategies considering project risk interdependence, In: International Journal of Project Management. Doi: 10.1016/j.ijproman.2016.03.001.

Zhang, Yao; Fan, Zhi-Ping. (2014). An optimization method for selecting project risk response strategies, In: International Journal of Project Management. pp 412-422. Doi: 10.1016/j.ijproman.2013.06.006. 